
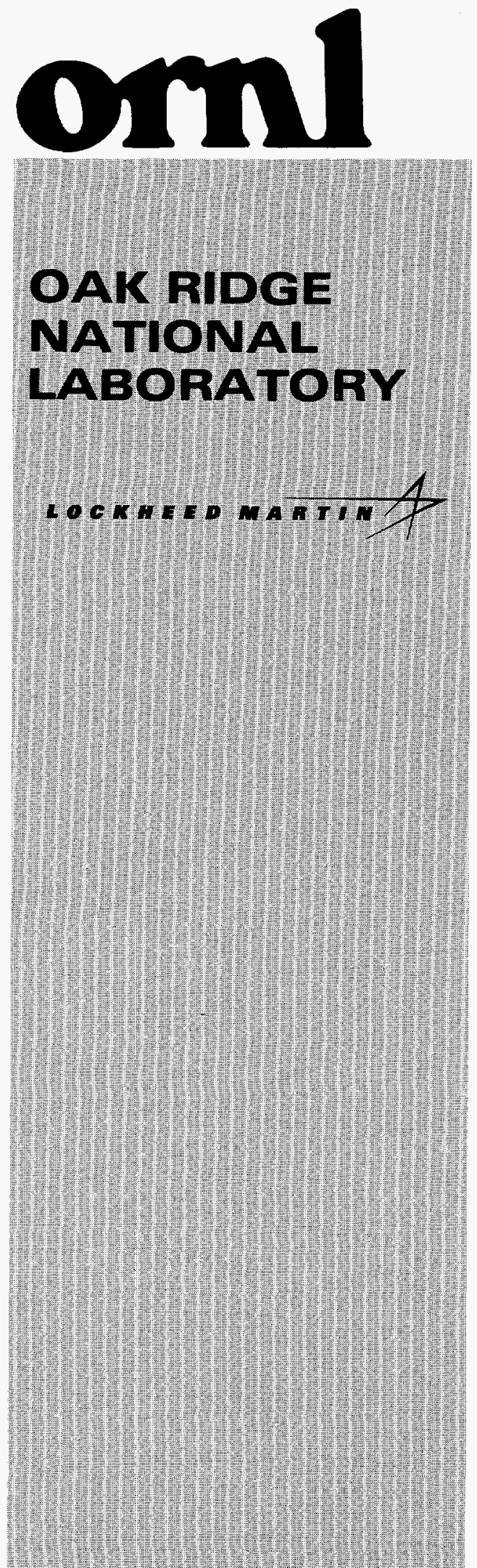

WMMGEO AMD OPERATEO BY LOCKHEED WARTW ENEROY RESEARCH CORPORATION FOR THE UNITED STATES

DEPARTHENT OF ENEREY
FEASIBLITY OF DEVELOPING A PORTABLE DRIVER PERFORMANCE DATA ACQUISITION SYSTEM FOR HUMAN FACTORS RESEARCH: DESIGN SPECIFICATIONS

\section{Prepared by the}

OAK RIDGE NATIONAL LABORATORY

Oak Ridge, Tennessee 37831 managed by

LOCKHEED MARTIN ENERGY RESEARCH CORPORATION for the

DEPARTMENT OF ENERGY

under contract number DE-AC05-96OR22464

\section{MASTER}

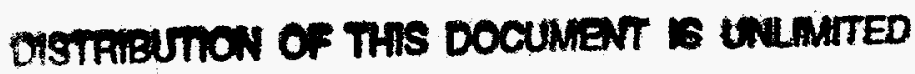




\section{DISCLAIMER}

Portions of this document may be illegible electronic image products. Images are produced from the best available original document. 
ORNL/TM-13540, Volume 3

\title{
FEASIBILITY OF DEVELOPING A PORTABLE DRIVER PERFORMANCE DATA ACQUISITION SYSTEM FOR HUMAN FACTORS RESEARCH: DESIGN SPECIFICATIONS
}

\author{
Richard J. Carter and Frank S. Barickman \\ Human Systems Research Group \\ Cognitive and Information Sciences Section \\ Computer Science and Mathematics Division
}

Manuscript Completed: March 1997

Date Published: January 1998

Research sponsored by the

U.S. Department of Transportation

National Highway Traffic Safety Administration

Office of Crash Avoidance Research

Heavy Vehicle and Driver Performance Research Division

COTR: Michael J. Goodman

under funding document DTNH22-92-X-07453

Prepared by the

OAK RIDGE NATIONAL LABORATORY

Oak Ridge, Tennessee 37831

managed by

LOCKHEED MARTIN ENERGY RESEARCH CORPORATION

for the

DEPARTMENT OF ENERGY

under contract number DE-AC05-960R22464 



\section{TABLE OF CONTENTS}

ABSTRACT

vii

1. INTRODUCTION

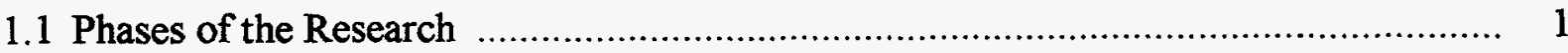

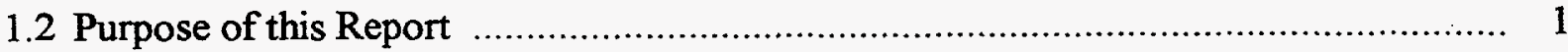

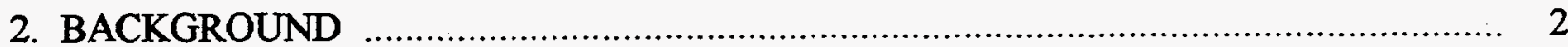

3. DESIGN SPECIFICATIONS FOR THE CONSTRUCTION OF DASCAR ............... 3

3.1 Data Acquisition Platform Design Specification ............................................ 3

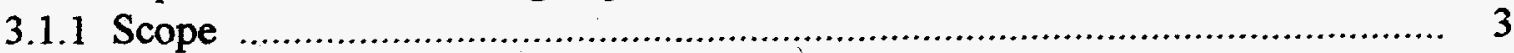

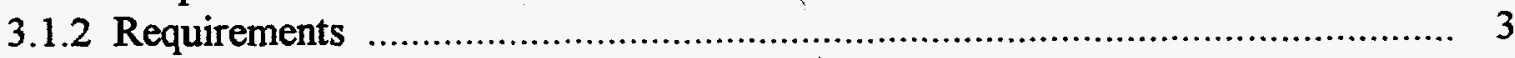

3.1.2.1 Item Definition ............................................................ 3

3.1.2.2 Characteristics .................................................................. 4

3.2 Data Storage and Communications Design Specifications ................................ 13

3.2.1 Radio Telemetry Design Specification .............................................. 13

3.2.1.1 Scope ..................................................................... 13

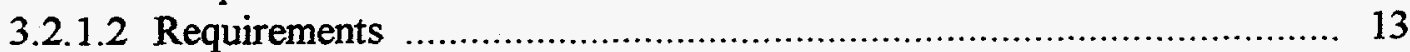

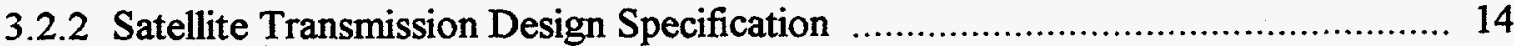

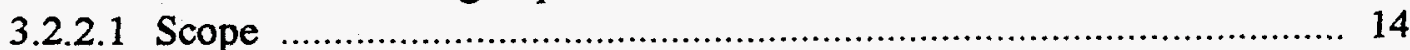

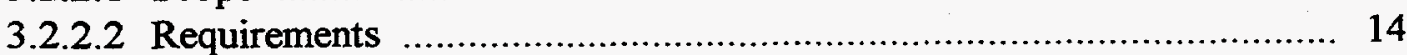

3.2.3 Personal Computer Design Specification .......................................... 16

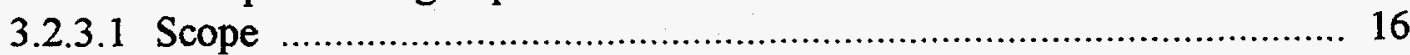

3.2.3.2 Requirements ................................................................ 16

3.2.4 Laptop Computer Design Specification ............................................ 17

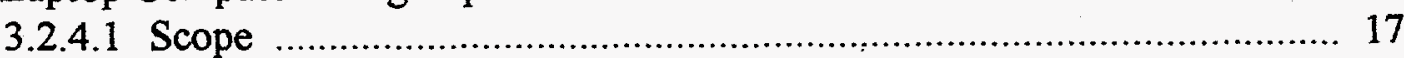

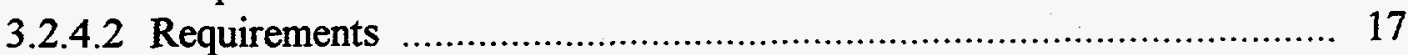

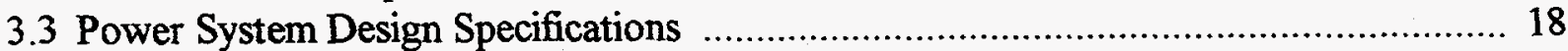

3.3.1 Battery Design Specification ........................................................... 18

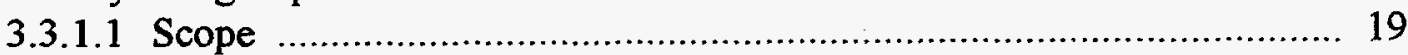

3.3.1.2 Requirements ............................................................. 19

3.3.2 Power Supply Design Specification ................................................... 20

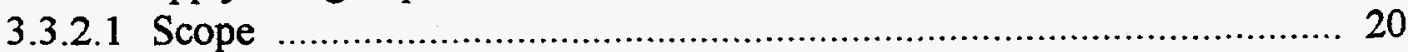

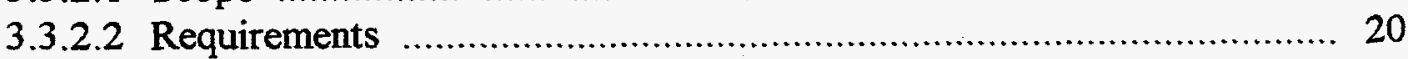

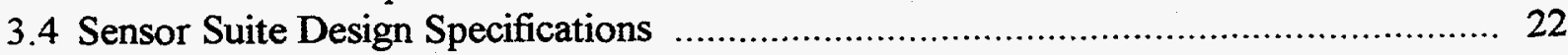

3.4.1 Linear Position Transducer Design Specification ...................................... 22

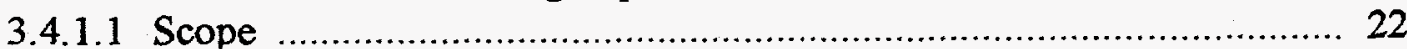

3.4.1.2 Requirements .............................................................. 22

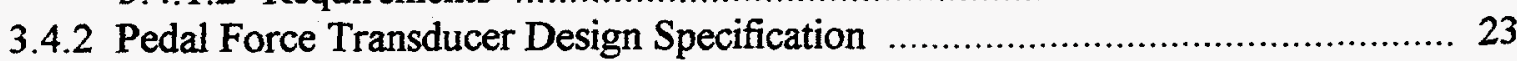

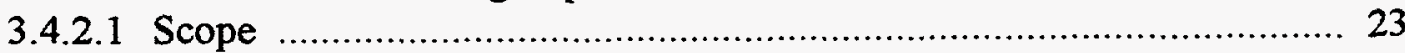

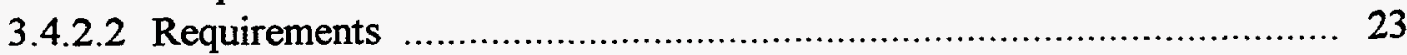




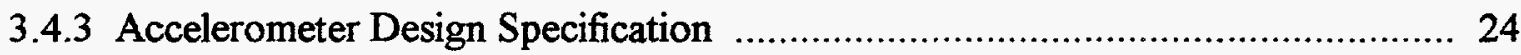

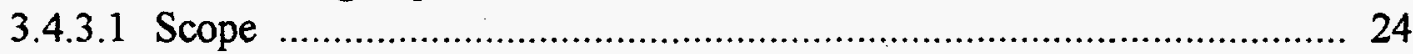

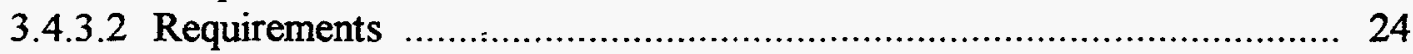

3.4.4 Ambulatory Data Recording System Design Specification …………………... 25

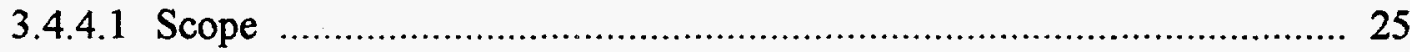

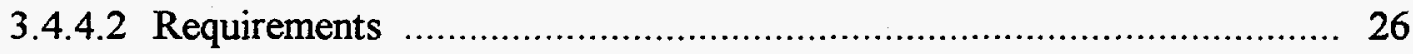

3.4.5 Six Degrees of Freedom Orientation Sensor Design Specification .................... 28

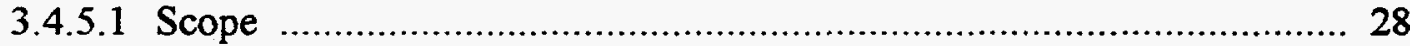

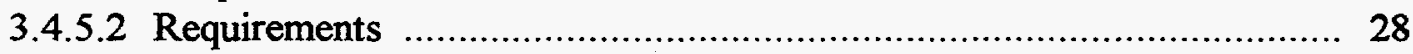

3.4.6 Hall-Effect Sensor Design Specification .................................................... 30

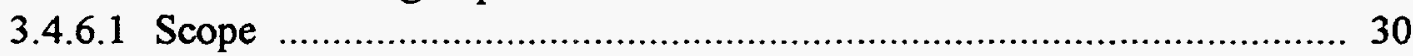

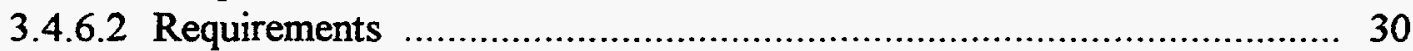

3.4.7 Electronic Compass Design Specification ..................................................... 31

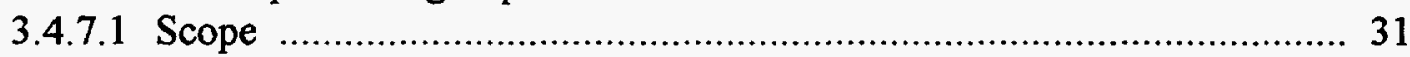

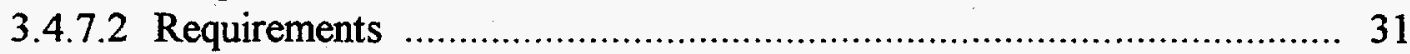

3.4.8 Range Sensors Design Specifications ……............................................... 33

3.4.8.1 Doppler Radar Sensor Design Specifications ….............................. 33

3.4.8.2 Laser Sensor Design Specification ............................................... 33

3.4.8.3 Controlaser Design Specification ................................................... 38

3.4.9 Radiometer/Photometer Design Specification ……....................................... 39

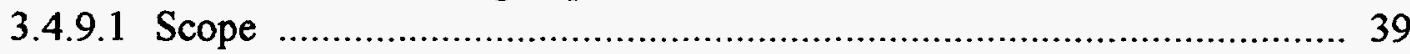

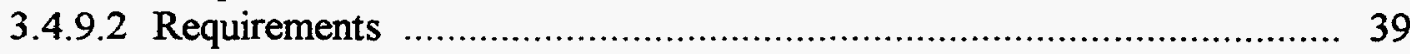

3.4.10 Sound Level Meter Design Specification …............................................. 40

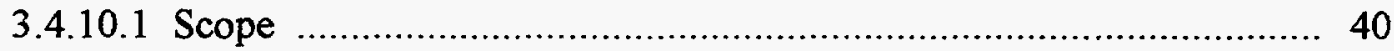

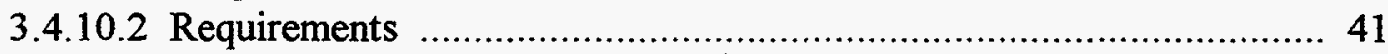

3.4.11 Meteorological Sensor Design Specification ........................................... 42

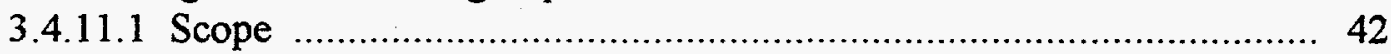

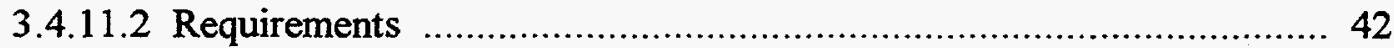

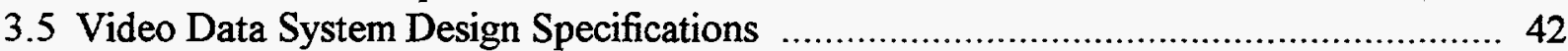

3.5.1 Micro Camera Design Specifications ………................................................... 42

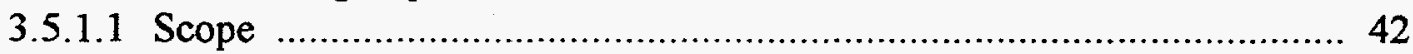

3.5.1.2 Requirements ..................................................................... 43

3.5.2 Vertical Time Code Generator Design Specification .................................... 47

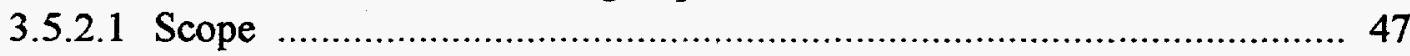

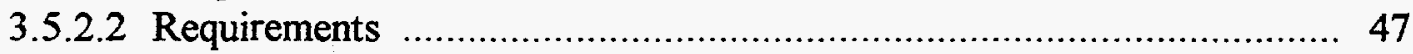

3.5.3 Quad Picture Processor Design Specification ................................................... 49

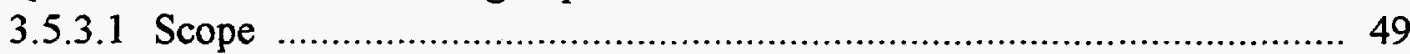

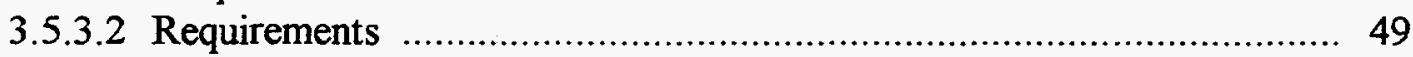

3.5.4 Compressed Video Digital Storage and Retrieval System Design Specification .. 50

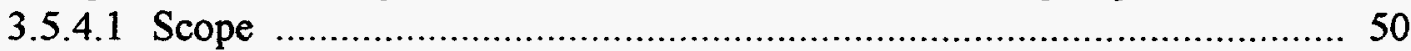

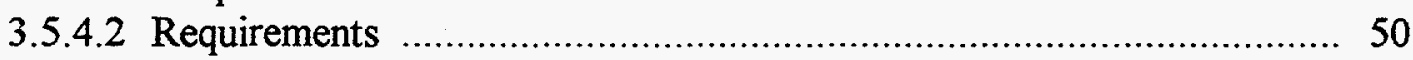

3.5.5 Super VHS Recorder Design Specification ................................................ 54

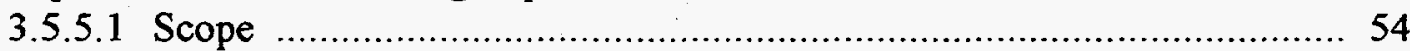





\begin{abstract}
A two-phase, multi-year research program entitled "development of a portable driver performance data acquisition system for human factors research" was recently completed. The primary objective of the project was to develop a portable data acquisition system for crash avoidance research (DASCAR) that will allow driver performance data to be collected using a large variety of vehicle types and that would be capable of being installed on a given vehicle type within a relatively short-time frame. During phase I a feasibility study for designing and fabricating DASCAR was conducted. In phase II of the research DASCAR was actually developed and validated. This technical memorandum documents the results from the feasibility study. It is subdivided into three volumes. Volume one addresses the last five items in the phase I research and the first issue in the second phase of the project. Volume two presents the related appendices. Volume three (this report) displays the design specifications developed for DASCAR during the "develop design requirements and specifications for a portable driver performance data acquisition system" task. Design specifications were assembled for each DASCAR element. The specifications were prepared in sufficient detail to allow a third party to use them to design, develop, procure, and subsequently construct the data acquisition system. This report also covers the background to the program. The data acquisition system is a portable, state-of-the art system which can be installed within virtually any passenger vehicle. It is both unobtrusive to the driver and inconspicuous to the outside world. DASCAR is currently capable of collecting and analyzing more than 60 driver-related, vehicular, and environment parameters and measures. DASCAR consists of six-major elements: a data acquisition platform, a data storage and transmission system, a power system, an equipment status bus, a sensor suite, and a video data system. A central data collection/analysis facility was also assembled to manage, support, and analyze data collected by the DASCAR prototype. DASCAR will be employed to collect normative driver performance data, support system performance guideline development, evaluate both conventional and intelligent transportation systems technologies, support simulator validation, and fine tune simulators.
\end{abstract}




\section{INTRODUCTION}

\subsection{Phases of the Research}

Oak Ridge National Laboratory recently completed a two phase, multi-year research and development program entitled "development of a portable driver performance data acquisition system for human factors research" for the United States Department of Transportation, National Highway Traffic Safety Administration (NHTSA), Office of Crash Avoidance Research. The primary objective of the project was to develop a portable data acquisition system for crash avoidance research (DASCAR) that will allow driver performance data to be collected using a large variety of vehicle models and types and that would be capable of being installed on a given vehicle type within a relatively short-time frame.

During phase I a feasibility study for designing and fabricating DASCAR was conducted. Human factors research needs were evaluated, and existing methods, measures, techniques, hardware, and software for evaluating the driver/vehicle/environment were identified. The tasks consisted of the following:

- Becoming familiar with NHTSA human factors research that would benefit from use of a portable data acquisition system.

- Identifying parameters and measures that could be collected.

- Identifying analysis tools and methods that could be used to assemble, analyze, and evaluate the gathered data in relation to safety issues.

- Identifying measurement techniques and state-of-the-art hardware and software to support development of an in-vehicle data acquisition system.

- Developing design requirements and specifications for a portable driver performance data acquisition system.

- Determining the cost of one or more copies of the proposed data acquisition system.

At the conclusion of phase I, it was determined by NHTSA that the construction of DASCAR was feasible at an acceptable cost. As a result, the second phase of the program was conducted. In phase II of the research, DASCAR was actually developed and validated. The phase consisted of the following steps:

- Designing a development plan and constructing the prototype driver performance data acquisition system.

- Preparing an evaluation plan.

- $\quad$ Conducting the evaluation, updating the system, and performing pilot research.

- Demonstrating and delivering the system, and training NHTSA staff.

\section{$1.2 \quad$ Purpose of this Report}

The primary purpose of this technical memorandum is to document the results from the feasibility 
study. It is subdivided into three volumes. Volume one addresses the last five items in the phase I research and the first issue in the second phase of the project. It describes and details the results from these six tasks. Volume two presents the related appendices. Volume three (this report) displays the design specifications developed for DASCAR during the "develop design requirements and specifications for a portable driver performance data acquisition system" task.

\section{BACKGROUND}

Given the diverse nature of circumstances leading to motor-vehicle crashes and the associated problem areas and issues, the development of effective collision-avoidance countermeasures can best be realized through a comprehensive knowledge and understanding of both the antecedent events which lead to crashes and the relative contributions of behavioral, vehicular, roadway, and environmental factors. In particular, the development of collision-avoidance countermeasures involving the application of new and innovative technologies represents a promising avenue for using knowledge and understanding to significantly reduce the incidence of crashes.

The evolution of effective advanced-technological countermeasures, however, goes hand-in-hand with the availability of a research tool to investigate the causes of crashes and the influence of vehicle-design characteristics on the relationships among the driver, the vehicle, the roadway, and the environment. This is particularly important where advanced-technology applications may themselves increase the potential for crashes or their severity under a given set of conditions.

The availability of this research tool is vital to fully understand and document the safety benefits and potential liabilities associated with a wide range of countermeasures and technological advancements, and to define the requirements associated with their design and implementation. Such a capability must allow for a flexible, comprehensive, and valid appraisal of countermeasures and advanced-technology applications.

In this regard, recent technological innovations and developments in computers, computer graphics, computational speed and power, miniaturization, communications, and data acquisition and analysis have provided the opportunity to develop DASCAR, a system for addressing the wide range of issues associated with existing problem areas as well as those involving the development and implementation of new advanced-technological systems within the motor vehicle-highway environment. These advances have also greatly enhanced the ability to develop the sophisticated tool needed to carry out a systematic and controlled evaluation of new technologies under operational or high-fidelity conditions.

NHTSA envisions many future situations in which the effectiveness and consequences of new intelligent-transportation systems technologies will need to be studied in actual production vehicles. Such studies will enable evaluations in vehicles which are familiar to drivers. These studies would be further enhanced by the availability of a DASCAR that can be easily installed in these vehicles to enable specific vehicle configurations of interest (e.g., pedal placement, head-up 
displays) to be evaluated, thereby increasing the variety of vehicle options (incorporating advanced technology) that are available for study. Ideally, an approach is needed that would allow data collection from a variety of vehicle models and types, and would address the issue of driver familiarity.

Such an approach is embodied in the concept of a DASCAR that can be installed in a wide range of vehicles within a relatively short period of time. As a universally adaptable system, it provides researchers with the ability to record information on driver, vehicle, roadway, and environmental parameters. Furthermore, it enables the measurement of driver performance in the driver's own vehicle, thereby ensuring vehicle familiarity. It is also possible to measure driver performance in relation to any vehicle design characteristic at relatively little expense and effort, and makes it easy to update existing models of driver/vehicle behavior to reflect performance characteristics in vehicles of current manufacture. The availability of such information can lead to improved problem identification in crash-avoidance research, as well as provide NHTSA with the capability to readily answer questions related to vehicle-design characteristics not otherwise available. In addition, such a system has the potential to measure driver performance as it relates to the location of surrounding vehicles. This will allow the study of how drivers interact with other vehicles in their immediate vicinity.

\section{DESIGN SPECIFICATIONS FOR THE CONSTRUCTION OF DASCAR}

Design specifications were assembled for each DASCAR element, except for the lateral-position lane tracking systems (because they are development efforts). The specifications were prepared in sufficient detail to allow a third party to use them to design, develop, procure, and subsequently construct the data acquisition system. The design specifications were generated using military standard (MIL-STD) 490 (Department of Defense, 1969) as a guideline. Specifications are presented below by category (i.e., data acquisition platform (DAP), storage and communications systems, power systems, sensor suite, and video data systems).

\subsection{Data Acquisition Platform Design Specification}

\section{1 .1 Scope}

This specification establishes the performance and design requirements for the DAP.

\subsubsection{Requirements}

\subsubsection{Item Definition}

The DAP shall consist of boards, cables, and signal processing equipment necessary to capture signals from the various sensors installed within and around the vehicle. It shall comprise one or more electronic enclosures with external electrical connectors. The DAP shall contain circuitry 
with the capability of accepting signals from driver, vehicle, and environment parametric sensors associated with DASCAR. The signals shall be converted from analog format and processed digitally. The digital information shall be output to a non-volatile memory containing the resultant analysis of the signals. Local access and control of the DAP and ancillary sensor interfaces shall be via a 486-based laptop computer. The digital information shall be stored in non-volatile memory for downloading and analysis on a 486-based personal computer (PC). Communication between the laptop and the PC shall be accomplished via credit card memory small computer system interface (SCSI) or by wireless means to include satellite transmission and radio telemetry. The DAP shall be powered by the DASCAR stand alone power supply.

\subsubsection{Characteristics}

\subsection{General Functional Requirements}

The DAP shall perform the following general functions.

\subsection{Driver Parameter Acquisition}

\subsection{1 Driver Control Actions}

\subsection{1.1 Accelerator/Throttle}

The DAP shall have the capability and capacity to acquire and process accelerator/throttle pedal position via a linear position transducer at the sampling rate of 20 hertz $(\mathrm{Hz})$.

\subsection{1.2 Brake Pedal}

The DAP shall have the capability and capacity to acquire and process brake pedal pressure via a pedal force transducer at the sampling rate of $20 \mathrm{~Hz}$.

\subsection{3 Steering Wheel}

The DAP shall have the capability and capacity to acquire and process steering wheel angle via a linear position transducer at the sampling rate of $20 \mathrm{~Hz}$.

\subsection{1.4 Non-instrumented Measures}

Brake pedal system line pressure, steering, and steering wheel torque may be considered for future implementation.

\subsection{2 Equipment Status Parameters}

\subsection{2.1 Auxiliary Device}


The DAP shall have the capability and capacity to acquire and process usage of auxiliary devices (e.g., side-object detection) via a number of sensors at the sampling rate of one $\mathrm{Hz}$.

\subsection{2.2 $\quad$ Brake Lights}

The DAP shall have the capability and capacity to acquire and process driver activation of the vehicle's brake lights via a sensor at the sampling rate of two $\mathrm{Hz}$.

\subsection{2.3 $\quad$ Hazard Flashers}

The DAP shall have the capability and capacity to acquire and process driver activation and deactivation of the vehicle's hazard flashers via a sensor at the sampling rate of two $\mathrm{Hz}$.

\subsection{2.4 $\quad$ Headlights}

The DAP shall have the capability and capacity to acquire and process driver activation and deactivation of the vehicle's headlights via a sensor at the sampling rate of one $\mathrm{Hz}$.

\subsection{2.5 $\underline{\text { Horn }}$}

The DAP shall have the capability and capacity to acquire and process driver activation of the vehicle's horn via a sensor at the sampling rate of two $\mathrm{Hz}$.

\subsection{2.6 $\quad$ Parking Lights}

The DAP shall have the capability and capacity to acquire and process driver activation and deactivation of the vehicle's parking lights via a sensor at the sampling rate of one $\mathrm{Hz}$.

\subsection{2.7 Rear Window Defogger/Wiper}

The DAP shall have the capability and capacity to acquire and process driver activation and deactivation of the vehicle's rear window defogger and wiper via two sensors at the sampling rate of one $\mathrm{Hz}$.

\subsection{2.8 $\quad$ Seat Belts}

The DAP shall have the capability and capacity to acquire and process seat belt usage via a sensor at the sampling rate of one $\mathrm{Hz}$.

\subsection{2.9 $\quad$ Turn Signals}

The DAP shall have the capability and capacity to acquire and process turn signal usage via a sensor at the sampling rate of two $\mathrm{Hz}$. 


\subsection{2.10 Windshield Wipers}

The DAP shall have the capability and capacity to acquire and process driver activation and deactivation of the vehicle's windshield wipers via a sensor at the sampling rate of two $\mathrm{Hz}$.

\subsection{2.11 Non-instrumented Equipment}

The following equipment may be considered for future implementation: air vents, ash tray, cellular telephone, cigarette lighter, clutch pedal, cruise control, emergency brake, engine, headlight dimmer switch, heater/air conditioning, radio/tape player/compact disk player, rearview mirror, transmission selector, windows, and windshield washer.

\subsection{3 Physiological Parameters}

\subsection{3.1 $\quad$ Core Temperature}

The DAP shall have the capability and capacity to acquire and process core temperature via an ambulatory data recording system (ADRS) at the sampling rate of two $\mathrm{Hz}$.

\subsection{3.2 Electrocardiogram}

The DAP shall have the capability and capacity to acquire and process rate and rate rise from an electrocardiogram via an ADRS at the sampling rate of five $\mathrm{Hz}$.

\subsection{3.3 Electroencephalogram}

The DAP shall have the capability and capacity to acquire and process alpha, beta, delta, and theta waves from an electroencephalogram via an ADRS at the sampling rate of five $\mathrm{Hz}$.

\subsection{3.4 Electromyogram}

The DAP shall have the capability and capacity to acquire and process tension levels and differential muscle activity from an electromyogram via an ADRS at the sampling rate of five $\mathrm{Hz}$.

\subsection{3.5 Electrooculogram}

The DAP shall have the capability and capacity to acquire and process eye blink rate from an electrooculogram via an ADRS at the sampling rate of $30 \mathrm{~Hz}$.

\subsection{3.6 Fidget Index}

The DAP shall have the capability and capacity to acquire and process the driver's movement in the seat via an accelerometer at the sampling rate of five $\mathrm{Hz}$. 
The DAP shall have the capability and capacity to acquire and process galvanic skin response via an ADRS at the sampling rate of five $\mathrm{Hz}$.

\subsection{8 Respiration}

The DAP shall have the capability and capacity to acquire and process respiration rate and volume via either an ADRS or a microwave Doppler-based system at the sampling rate of five $\mathrm{Hz}$.

\subsection{3.9 $\quad \underline{\text { Skin Temperature }}$}

The DAP shall have the capability and capacity to acquire and process skin temperature via an ADRS at the sampling rate of two $\mathrm{Hz}$.

\subsection{3.10 Non-instrumented Parameters}

Acceleration at the driver's head, blood pressure, and gross body activity may be considered for future implementation.

\subsection{Vehicle Parameter Acquisition}

\subsection{1 Acceleration}

The DAP shall have the capability and capacity to acquire and process the vehicle's lateral, longitudinal, and vertical acceleration via a six-degrees of freedom (DOF) orientation sensor at the sampling rate of $20 \mathrm{~Hz}$.

\subsection{Distance Traveled}

The DAP shall have the capability and capacity to acquire and process the distance traveled by the vehicle via a Hall-effect sensor at the sampling rate of one $\mathrm{Hz}$.

\subsection{3 Elapsed Time}

The DAP shall have the capability and capacity to acquire and process the elapsed time via the laptop computer's clock at the sampling rate of two $\mathrm{Hz}$.

\subsection{4 Heading}

The DAP shall have the capability and capacity to acquire and process the vehicle's heading via an electronic compass at the sampling rate of $20 \mathrm{~Hz}$. 


\subsection{5 Headway}

The DAP shall have the capability and capacity to acquire and process the vehicle's headway via either a Doppler radar, a laser, or a controlaser range sensor at the sampling rate of $20 \mathrm{~Hz}$.

\subsection{6 Lateral Lane Keeping}

The DAP shall have the capability and capacity to acquire and process the vehicle's lateral position within a lane via a lateral-position lane tracking system at the sampling rate of $20 \mathrm{~Hz}$.

\subsection{7 Pitch}

The DAP shall have the capability and capacity to acquire and process the vehicle's pitch via a sixDOF orientation sensor at the sampling rate of $20 \mathrm{~Hz}$.

\subsection{8 $\underline{\text { Roll }}$}

The DAP shall have the capability and capacity to acquire and process the vehicle's roll via a sixDOF orientation sensor at the sampling rate of $20 \mathrm{~Hz}$.

\subsection{9 Tailway}

The DAP shall have the capability and capacity to acquire and process the vehicle's tailway via either a Doppler radar, a laser, or a controlaser range sensor at the sampling rate of $20 \mathrm{~Hz}$.

\subsection{10 Time-to-Collision}

The DAP shall have the capability and capacity to acquire and process time-to-collision data via a either a Doppler radar, a laser, or a controlaser range sensor at the sampling rate of two $\mathrm{Hz}$.

\subsection{11 Vehicle Location}

The DAP shall have the capability and capacity to acquire and process the vehicle's location via a global positioning system (GPS) receiver at the sampling rate of one $\mathrm{Hz}$.

\subsection{12 Velocity}

The DAP shall have the capability and capacity to acquire and process the vehicle's forward velocity via a Hall-effect sensor at the sampling rate of $20 \mathrm{~Hz}$. 


\subsection{13 Yaw}

The DAP shall have the capability and capacity to acquire and process the vehicle's yaw via a sixDOF orientation sensor at the sampling rate of $20 \mathrm{~Hz}$.

\subsection{Non-instrumented Parameters}

The following parameters may be considered for future implementation: braking, engine torque, path, pitman arm, sideslip, steering, suspension, throttle, and wheel rotation.

\subsection{Environment Parameter Acquisition}

\subsection{1 Barometric Pressure}

The DAP shall have the capability and capacity to acquire and process barometric pressure of the outside environment via a meteorological sensor at the sampling rate of two $\mathrm{Hz}$.

\subsection{2 Humidity}

The DAP shall have the capability and capacity to acquire and process humidity of the outside environment via a meteorological sensor at the sampling rate of two $\mathrm{Hz}$.

\subsection{3 Illumination}

The DAP shall have the capability and capacity to acquire and process the illumination of the outside environment via a radiometer/photometer at the sampling rate of two $\mathrm{Hz}$.

\subsection{4 Lumination}

The DAP shall have the capability and capacity to acquire and process lumination from the outside environment via a radiometer/photometer at the sampling rate of two $\mathrm{Hz}$.

\subsection{5 Noise/Sound}

The DAP shall have the capability and capacity to acquire and process steady state and impulse noise and sound, as heard by the driver in the vehicle, via a sound level meter at the sampling rate of two $\mathrm{Hz}$.

\subsection{6 Road Gradient}

The DAP shall have the capability and capacity to acquire and process road-gradient inclination angles via a six-DOF orientation sensor at the sampling rate of two $\mathrm{Hz}$. 


\subsection{7 Temperature}

The DAP shall have the capability and capacity to acquire and process outside temperature via a meteorological sensor at the sampling rate of one $\mathrm{Hz}$.

\subsection{8 Time of Day}

The DAP shall have the capability and capacity to acquire and process the time of the day via the laptop computer's clock at the sampling rate of one $\mathrm{Hz}$.

\subsection{9 Wind Direction and Speed}

The DAP shall have the capability and capacity to acquire and process wind direction and speed via a meteorological sensor at the sampling rate of two $\mathrm{Hz}$.

\subsection{10 Non-instrumented Parameters}

The following parameters may be considered for future implementation: delineation, hand positions, haze/dust, precipitation, road conditions, road surfaces, traffic conditions, contrast, reflectance, and eye and head movements.

\subsection{Non-volatile Memory}

The non-volatile memory of the DAP shall take the form of an industry standard card flash (electronic processing read-only memory - EPROM) or card SPAM that is recoverable from the unit for download of data from the DAP to the laptop computer. The card memory shall conform to Personal Computer Memory Card International Association (PCMCIA) interface specifications. Data written into the non-volatile memory shall conform to the disk operating system (DOS) file format. The non-volatile memory shall be programmed with the DAP operating software and configuration information detailing the location of sensors for particular applications.

\subsection{System Interfaces}

The DAP hardware/software shall be capable of accommodating two data bus standards, the RS232 and RS-422 digital data interfaces.

\subsection{Detailed Performance Specifications}

The DAP shall meet the following specifications.

\subsection{Discrete Generalized Analog Inputs}


Number of channels: 42 .

Interface: differential balanced input.

Simultaneously acquired and processed: one.

Maximum voltage range: 28 volts (V) differential.

Minimum voltage input: to be specified.

Input protection: The DAP shall tolerate shorts to ground, shorts across the input pair, and shorts to external voltage sources up to $+/-40 \mathrm{~V}$.

Frequency range: direct current (DC).

Required input impedance: $10,000 \mathrm{ohm}$ minimum.

Required input to input isolation: $200,000 \mathrm{ohm}$ minimum.

Common mode rejection: -60 decibels $(\mathrm{dB})$ from 10 to $10,000 \mathrm{~Hz}$.

\subsection{2 $\quad$ Synchro/Resolve}

Type of input: three wire synchronization.

Number of synchros: three.

Simultaneously acquired and processed: one.

Input voltage: $11.8 \mathrm{~V}$ alternating current $(\mathrm{AC})$.

Input reference frequency: $400 \mathrm{~Hz}$.

Accuracy: eight minutes.

Resolution: 12 bits.

\subsection{Non-volatile Storage}

Type: "credit card" user removable portable non-volatile memory.

Number of slots: one.

Memory capacity: four megabytes $(\mathrm{Mb})$.

Data format: PC DOS file format.

Interface format: PCMCIA standard.

\subsection{Communications}

\subsection{1 $\underline{\text { RS-232 }}$}

Standard electrical interface capable of an interface to radio telemetry and a portable satellite antenna. Specification with software protocol as follows:

Number of bits: eight.

Stop bits: two.

Parity: ibit and even. 


\subsection{2 RS-422}

Standard electrical interface; specification with software protocol as follows:

Number of bits: eight.

Stop bits: two.

Parity: ibit and even.

\subsection{Processing}

\subsection{1 Asynchronous Signal Processing}

Frequency ranges for Fast Fourier Transforms (FFT): 50 to $43,680 \mathrm{~Hz}$ in 1-2-5 sequence in steps that produce rational resolution bin values. The FFT resolution transform size shall be selectable from $200,400,800,1,600,3,200$, or 6,400 point FFT. This capability allows the optimum trade between frequency and processing time.

Window types: Kaiser Bessel, flattop, and rectangular. The selection of window type allows the trade-off between frequency discrimination and amplitude linearity. Averaging modes: root-mean square (RMS) and linear.

Number of averages: 1 to 32 FFT or maximum memory in integer steps. This capability allows the reduction of transient or random noise.

Overlap: 0 to $7 / 8$ in $1 / 8$ increments. This capability allows a trade-off between reduction of data collection time and input signal correlation.

\subsection{2 Synchronous Signal Processing}

\subsection{2.1 Power Averaged Processing}

Frequency ranges: 50 to $43,680 \mathrm{~Hz}$ in 1-2-5 sequence in steps that produce rational resolution bin values.

Frequency resolution $(R)$ : selectable from $1 / 8 \mathrm{R}$ (400 point) to $1 / 128 \mathrm{R}$ (6,400 point) for the resolution increments given above. This capability allows the discrimination of harmonically related components which are very close in frequency.

Window types: Kaiser Bessel, flattop, and rectangular.

Averaging modes: RMS, linear, and coherent.

Number of averages: 1 to 32 FFT or maximum memory in integer steps.

Overlap: 0 to $7 / 8$ in $1 / 8$ increments.

Maximum order: $50 \mathrm{R}$ (at maximum frequency).

\subsection{2.2 $\quad$ Time Averaged Processing}

Frequency ranges: 50 to $43,680 \mathrm{~Hz}$ in $1-2-5$ sequence in steps that produce rational resolution bin values. 
Frequency ranges: 1.1 to $43,680 \mathrm{~Hz}$.

Frequency resolution: $1 / \mathrm{R}$ or $1 / 4 \mathrm{R}$.

Averaging modes: time or coherent.

Number of averages: 1 to 512 revolutions or maximum memory in integer steps.

Maximum order: $12 \mathrm{R}$ or $32 \mathrm{R}$ (at the maximum frequency).

\subsection{Power Requirements}

The DAP shall utilize host system power. The total DAP input power is $+28 \mathrm{~V} \mathrm{DC}$ with a DC/DC converter.

\subsection{Data Storage and Communications Design Specifications}

\subsubsection{Radio Telemetry Design Specification}

\subsubsection{1 $\quad \underline{\text { Scope }}$}

This specification establishes the performance and design requirements for radio telemetry.

\subsubsection{Requirements}

\subsubsection{1 $\quad$ Item Definition}

The radio telemetry shall consist of boards, cables, antennas, and power supplies necessary to transmit digital data from the laptop computer installed within the vehicle to a PC located a few kilometers away from the vehicle. It shall comprise two or more electronic enclosures with external electrical connectors and have a high-speed radio transceiver and a network controller. The radio telemetry shall be a wireless asynchronous replacement for the RS-232 link and utilize spread spectrum radio frequency communications technology. It shall not require a Federal Communications Commission (FCC) site license and line-of-sight positioning. The radio telemetry shall have multiple channel options and built-in network protocols to support numerous modules operating simultaneously without interfering with each other. Baud rates and flow control options shall be selectable and saved in non-volatile memory. The radio telemetry shall be able to be paired in a simple "pass through" point-to-point mode or operated in various other topologies. It shall be powered by the DASCAR stand alone power supply.

\subsection{Characteristics}

\subsection{Detailed Performance Specifications}

The radio telemetry shall meet the following specifications. 


\subsection{1 Serial Interface}

Data rates: $1,200,2,400,4,800,9,600$, and 19,200 (full duplex) baud.

Data format: eight data bits, no parity, and one bit stop.

Connector: nine-pin female $\mathrm{D}$ connector.

Flow control: CTS, DSR, and XON/XOFF.

\subsection{2 Radio}

Power output: 500 milliwatts (nominal).

Data rate: 121,000 bits per second (bps).

Independent channels: four.

Range: up to $244+$ meters.

Frequency band: 902 - 928 megahertz $(\mathrm{MHz})$.

\subsection{3 Power Requirements}

Power connector: 2.5 millimeter female DC power jack.

Voltage: nine $\mathrm{V}(9.5 \mathrm{~V}$ maximum).

Maximum current: 350 milliamperes (mA).

Typical current: $150 \mathrm{~mA}$.

\subsection{4 Packaging}

Antenna: 9.2075 centimeters.

Module size (without an antenna): $10.2 \times 16.5 \times 1.9$ centimeters.

Weight (with an antenna): 340 grams.

Status light emitting diodes (LED): power, carrier detect, and receive data.

\subsection{5 Environment}

Temperature (operating/storage): -20 to +60 degrees Celsius (C) / -50 to +85 degrees C. Relative humidity: 20 to $90 \%$ (non-condensing).

\subsubsection{Satellite Transmission Design Specification}

3.2.2.1 $\quad$ Scope

This specification establishes the performance and design requirements for satellite transmission.

3.2.2.2 $\quad$ Requirements

3.2.2.2.1 $\quad$ Item Definition 
The satellite transmission equipment shall consist of boards, cables, antennas, and power supplies necessary to transmit digital data from the laptop computer installed within the vehicle and the compressed video digital storage and retrieval system (CVDSRS) to a PC located hundreds, possibly, thousands, of kilometers away from the vehicle. It shall comprise one or more electronic enclosures with external electrical connectors for standard RS-232 interface to National Electrical Manufacturer's Association (NEMA) 0183 navigators and GPS interface to a 50-ohm SMA connector. The satellite transmission equipment shall provide global data communication through the Inmarsat standard ' $C$ ' satellite system. It shall provide for two-way transfer of digital data to any destination, data reporting transmission, and automatic polling of terminal position. The satellite transmission equipment shall be powered by the DASCAR stand alone power supply.

\subsection{Characteristics}

\subsection{Detailed Performance Specifications}

The satellite transmission equipment shall meet the following specifications.

\subsection{1 System Specifications}

Transmit frequency: 1626.5 to $1646.5 \mathrm{MHz}$.

Receive frequency: 1530.0 to $1545.0 \mathrm{MHz}$.

Channel spacing: five kilohertz $(\mathrm{kHz})$.

\subsection{2 Indoor Unit Specifications}

Modulation: 1,200 symbols/second BPSK

Ambiguity resolution: unique word.

Coding: rate $1 / 2, k=$ seven convolutional code with interleaved code symbols.

Data rate: 600 bps.

Receive frame length: 8.6 seconds.

Transmit signaling access mode: slotted ALOHA.

Transmit message channel: TDMA and FDMA, interleaved code symbol.

Terminal interface: International Telegraph and Telephone Consultative Committee (CCITT) recommended V 24/28, nine-pin female D connector, 110 - 9,600 baud, ITAfive code, maximum 100 meter cable.

Printer interface: standard parallel Centronics, 25-pin female D connector, maximum four meter cable.

Navigator and alarm interface: CCITT recommended V 10 special with NEMA 0183 interface and multidrop addressing, BNC-female connector, maximum 100 meter cable. Antenna interface: standard 50-ohm female N-connector, maximum 100 meter cable. Memory: 256 kilobytes ( $\mathrm{kb}$ ) random access memory (RAM).

System programming: EPROM programming of installation parameters from operator's terminal. 
DC power source: 10.5 to $32 \mathrm{~V} \mathrm{DC}, 9.5 / 80$ watts (W).

Ambient temperature: -25 to +55 degrees $\mathrm{C}$ operating; -40 to +80 degrees $\mathrm{C}$ storage.

Relative humidity: $95 \%$ (non-condensing).

Vibration: operational: random 5 to $20 \mathrm{~Hz}, 0.02$ gravity (g) (squared)/Hz, 20 to $150 \mathrm{~Hz}$ $3 \mathrm{~dB} /$ Oct.; survival: random 5 to $20 \mathrm{~Hz}, 0.05 \mathrm{~g}$ (squared)/ $\mathrm{Hz}, 20$ to $150 \mathrm{~Hz}-3 \mathrm{~dB} /$ Oct.

Shock: half sine, $20 \mathrm{~g} / 11$ milliseconds.

Mounting: free standing cabinet with mounting brackets or optional 48-centimeter mounting kit.

Dimensions: 6.1 (height) $\times 21.6$ (width) $\times 27.9$ (depth) centimeters.

Weight: 3.19 kilograms.

\subsection{3 Antenna Specifications}

Weight: 1.9 kilograms.

Height: 17.53 centimeters.

Maximum diameter: 14.99 centimeters, conical.

Ambient temperature: -35 to +55 degrees $C$ operational; -40 to +70 degrees $C$ storage.

Spray: solid droplets

Ice: up to 2.5 centimeters.

Precipitation: up to 10 centimeters/hour.

Wind: up to 100 knots.

Vibration: 2 to $10 \mathrm{~Hz}$, one g peak.

Mounting: $1-1 / 2$ inches tube mounting.

\subsubsection{Personal Computer Design Specification}

\subsubsection{1 $\quad \underline{\text { Scope }}$}

This specification establishes the performance and design requirements for the PC.

\subsubsection{2 $\quad$ Requirements}

\subsubsection{1 $\quad \underline{\text { Item Definition }}$}

The PC shall consist of hardware and software necessary to assemble and store the digital data received via credit card memory SCSI and/or transmitted via radio telemetry and satellite transmission from the laptop computer installed within the vehicle. It shall be 486 based and consist of both hard and floppy disk drives, a color video monitor, and two operator input devices (i.e., keyboard and mouse). The PC shall have enough memory to integrate, analyze, evaluate, and interpret the parameter data collected via the DASCAR sensor suite.

\subsection{Characteristics}




\subsection{Detailed Performance Specifications}

The PC shall meet the following specifications.

Central processing unit (CPU): Intel $486 \mathrm{DX} 2-66 \mathrm{MHz}$.

Memory: $16 \mathrm{Mb}$ RAM (expandable to $64 \mathrm{Mb}$ ), $256 \mathrm{~kb}$ level two cache.

Hard disk drive: $340 \mathrm{Mb} \mathrm{IDE}$.

Floppy disk drives: dual 3.5 inch $(1.44 \mathrm{Mb})$ and 5.25 inch $(1.2 \mathrm{Mb})$ disk drives.

Video display adapter: one Mb VESA local bus video accelerator (optional two Mb video memory), resolution up to $1280 \times 1024$, refresh rates of over $70 \mathrm{~Hz}$.

Video display: 43 centimeter non-interfaced color super-video graphics array monitor (0.28 millimeter dot pitch).

Memory architecture: 32-bit memory architecture; 36-bit, 72-pin SIMMs with parity; 4, 8,16 , and $32 \mathrm{Mb}$ SIMMs; two SIMM sockets.

Basic input output system (BIOS): American Megatrends, Incorporated system and keyboard BIOS; support multi-sector reads to enhance hard drive performance; system and video BIOS shadowing; built-in setup program.

Expansion bus: seven 16-bit ISA slots; two slots with VL-bus extension; one slot used for video card - all other slots open.

Desktop chassis: small footprint desktop chassis; 40.6 (width) $\times 41.9$ (depth) $\times 16.5$ (height) centimeters; three 5.25 inch HH drive bays; two internal 3.5 inch drive bays; plated steel; $200 \mathrm{~W}$ power supply; and approximately 11.34 kilograms.

Environmental: -10 to +35 degrees $\mathrm{C}$ and 8 to $80 \%$ non-condensing humidity.

Regulatory: FCC class A; approved for business use only; and FCC class B pending. Environmental Protection Agency (EPA) energy star: energy saving mode to reduce power consumption to less than $24 \mathrm{~W}$; unique power control circuitry to make any monitor energy star compliant; and timed or instant access to power conservation mode. Service and support: two year's parts warranty; first year on-site service; optional warranty extension; and lifetime toll free technical support.

Other features: Microsoft DOS 6.2 and Windows 3.1; two-button Microsoft compatible mouse; two 16552 serial and one EPP/ECP parallel ports; a 101-key enhanced keyboard with separate numeric and cursor keypads; EMS LIM 4.0 support; and dual floppy controller.

\subsubsection{Laptop Computer Design Specification}

\subsubsection{1 $\quad \underline{\text { Scope }}$}

This specification establishes the performance and design requirements for the laptop computer.

\subsubsection{Requirements}

\subsubsection{1 $\quad$ Item Definition}


The laptop computer shall consist of hardware and software necessary to receive, assemble, and temporarily store the digital data transmitted from the DAP. It shall be 486 based and consist of both a floppy and a hard disk drive, a monochromatic video monitor, and two operator input devices (i.e., keyboard and track ball). The laptop computer shall have sufficient memory to integrate the parameter data collected via the DASCAR sensor suite, but small enough that it can be mounted inside the vehicle. It shall be powered by the DASCAR stand alone power supply.

\subsection{Characteristics}

\subsection{Detailed Performance Specifications}

The laptop computer shall meet the following specifications.

CPU: 32-bit Intel $486 \mathrm{DX2}-66 \mathrm{MHz}$.

Hard disk drive: $340 \mathrm{Mb}, 12$ milliseconds IDE.

Memory: eight $\mathrm{Mb}$ (upgradeable to $32 \mathrm{Mb}$ ).

Display interface: 32-bit local-bus Windows accelerator, one Mb RAM.

Monochromatic liquid crystal display (LCD): edge-lit supertwist with 64 shades of gray.

Keyboard: full-sized 85-key, with cursor keys in inverted $\mathrm{T}$.

Track ball: integral 16 millimeter diameter, front center mounted.

PCMCIA slots: two PCMCIA type II or one PCMCIA type III.

Input/output ports: one parallel, two serial.

Floppy disk drive: 3.5 inch, $1.44 \mathrm{Mb}$.

Power requirements: voltage $-115-230 \mathrm{~V} \mathrm{AC}$, frequency $-50-60 \mathrm{~Hz}$.

Power usage: $<10 \mathrm{~W}$ in standby mode, conform to EPA energy star guidelines.

Battery type and life: nickel-cadmium/NIMH, two to five hours.

Preinstalled software: Microsoft DOS 6.0 and Windows 3.1.

Dimensions: $28.19 \times 21.79 \times 4.50$ centimeters.

Weight: 2.89 kilograms with battery.

Environmental range: operating: temperature -10 to +35 degrees $C$; shock -five g; vibration -one g peak, $3-2,000 \mathrm{~Hz}$; non-operating: temperature -1 to +60 degrees $\mathrm{C}$; shock - $60 \mathrm{~g}$; vibration $-1.5 \mathrm{~g}$ peak, $3-2,000 \mathrm{~Hz}$.

Regulatory: Underwriter's Laboratories (UL) and CSA approved FCC class B.

Warranty: one year.

\subsection{Power System Design Specifications}

\subsubsection{Battery Design Specification}

\subsubsection{1 $\underline{\text { Scope }}$}

This specification establishes the performance and design requirements for the battery. 


\subsubsection{2 $\quad \underline{\text { Requirements }}$}

\subsection{Item Definition}

The battery shall consist of cells necessary to provide the required power for volatile memory preservation during power-down of the DASCAR. It shall serve a power-smoothing function, absorbing any ripples and spikes which occur as a result of irregularities in the vehicle charging system and compensate for lowered voltages which occur, for example, when the vehicle sits in traffic with the air conditioner going in the summer. The battery shall be a sealed, rechargeable lead-acid type and consist of one or more battery enclosures/cases with external electrical connectors.

\subsection{Characteristics}

\subsection{General Functional Requirements}

The battery shall perform the following general functions.

\subsection{1 Sealed/Maintenance-free}

The battery shall be constructed so that it allows trouble-free, safe operation in any position. It shall be sealed and made of a leak-proof material. There shall be no need to add an electrolyte to the battery.

\subsection{2 Easy Handling}

No special handling precautions or shipping containers shall be required.

\subsection{3 Long Service Life}

Under normal operating conditions, the battery's dependable service life shall be expected to be between four and five years in standby applications and between 200 and 1,000 charge/discharge cycles depending upon depth of discharge.

\subsection{4 Design Flexibility}

The battery shall be able to be used in series and/or parallel in order to provide a choice of voltages and capacity.

\subsection{5 Rugged Construction}

The battery shall have a high-impact resistant case made of non-conductive ABS plastic. The case shall provide superior resistance to shock, vibration, chemicals, and heat. 


\subsection{6 Compact}

The battery shall be designed utilizing state-of-the-art technology, high-grade materials, and a carefully controlled plate-making process thus providing excellent output per cell, and superior power/volume and power/weight ratios.

\subsection{7 High Discharge Rate}

The battery shall have low internal resistance thus allowing currents of more than ten times the rated capacity of the battery.

\subsection{8 Long Shelf Life}

The battery shall have a low self-discharge rate thus permitting storage of fully charged batteries for up to a year at room temperature before charging is required.

\subsection{9 Deep Discharge Recovery}

The battery shall have special separators, advanced plate composition, and a carefully balanced electrolyte system in order to greatly improve the capability of recovering from deep discharge.

\subsection{Detailed Performance Specifications}

The battery shall meet the following specifications.

Terminals: quick disconnect tabs, $0.475 \times 0.081$ centimeters.

Nominal voltage: $12 \mathrm{~V}$.

Capacity (ampere (A)-hours): 20 hour rate -2.7 to $26.0 ; 10$ hour rate -2.5 to 25.0 .

Discharge current at 10 hour rate: 250 to $2,500 \mathrm{~mA}$.

Dimensions (length, width, height, and weight): 10.16 to 27.00 centimeters, 3.76 to 13.84

centimeters, 6.68 to 18.19 (excludes battery tabs) centimeters, and 1.11 to 10.11

kilograms.

Operating temperature range: -24 to +60 degrees $\mathrm{C}$.

\subsubsection{Power Supply Design Specification}

\subsubsection{1 $\quad \underline{\text { Scope }}$}

This specification establishes the performance and design requirements for the power supply.

\subsubsection{Requirements}

3.3.2.2.1 $\quad$ Item Definition 
The power supply shall consist of boards necessary to provide the required voltages and power input for the various components of the DASCAR. It shall be a DC to DC power converter and use a forward converter switching at zero-current topology. The power supply shall be a stand alone unit and consist of one or more electronic enclosures with external electrical connectors. It shall be compact, simple, and flexible.

\subsection{Characteristics}

\subsection{Detailed Performance Specifications}

The power supply shall meet the following specifications.

\subsection{1 Electrical Characteristics}

Set point accuracy: $0.5 \%$.

Load regulation: $0.005 \%$.

Line regulation: $0.005 \%$.

Output temperature drift: $0.01 \% /$ degree C.

Peak to peak output ripple: $1 \%$.

High trim/program: $110 \%$.

Low trim/program: $5 \%$.

Total remote sense compensation: $0.5 \mathrm{~V}$.

OVP set point: $125 \%$.

Current limit: $115 \%$.

\subsection{2 Family Features}

Inputs: 10 to $400 \mathrm{~V} \mathrm{DC}$.

Any output: 2 to $95 \mathrm{~V} \mathrm{DC}$.

Dimensions: $18.54 \times 12.45 \times 1.57$ centimeters.

Up to $13,950 \mathrm{~W} / \mathrm{square}$ meter.

150 to $600 \mathrm{~W}$.

Regulatory: UL, CSA, and TUV.

$80-90 \%$ efficiency.

Chassis mount.

Remote sense.

Thermal shutdown.

Current limit and OVP.

ZCS power architecture

Low noise frequency modulation (FM) control. 


\subsection{Sensor Suite Design Specifications}

\subsubsection{Linear Position Transducer Design Specification}

\subsubsection{1 $\quad \underline{\text { Scope }}$}

This specification establishes the performance and design requirements for the linear position transducer.

\subsubsection{2 $\quad$ Requirements}

\subsection{Item Definition}

The linear position transducer shall consist of a small diameter stainless steel cable which is wrapped onto a drum. It shall be used to collect accelerator/throttle and steering wheel data from the vehicle. The linear position transducer shall be environmentally sealed and have digital position output. It shall be powered by a DC voltage input provided by the DASCAR stand alone power supply.

\subsection{Characteristics}

\subsection{General Functional Requirements}

Operationally, the linear position transducer shall be mounted at a fixed position and a clip on the end of the stainless steel cable shall be attached to a moveable element. As movement occurs the cable shall extend from the transducer while rotating a sensing element connected to the internal drum. An electrical output signal shall be produced which is directly proportional to the cable extension. An internal spring shall maintain near constant tension on the cable and serve as the retraction mechanism.

\subsection{Detailed Performance Specifications}

The linear position transducer shall meet the following specifications.

\subsection{1 General Information}

Linearity: 5 and 13 centimeter ranges: $+/-0.25 \%$ full scale; $25,38,51$, and 64 centimeter ranges: $+/-0.15 \%$ full scale; and all other ranges: $+/-0.10 \%$ full scale; repeatability: $+/-$ $0.015 \%$ full scale.

Resolution: ranges 25 centimeters and above - essentially infinite.

Range: 0 to 203 centimeters.

Construction: anodized aluminum and stainless steel.

Sensing device: precision potentiometer. 
Connector: MS3102E-14S-6P.

Mating connector: MS3106E-14S-6S.

\subsection{2 Electrical}

Input impedance: $500 \mathrm{ohms}+/-10 \%$.

Output impedance: 0 to $500 \mathrm{ohms}$.

Excitation voltage: $25 \mathrm{~V}$ maximum $\mathrm{AC}$ or $\mathrm{DC}$.

\subsection{3 Environmental}

Thermal coefficient of sensing element: $+/-100 \mathrm{PPM} /$ degree $\mathrm{C}$ maximum.

Operating temperature: -15 to +95 degrees $\mathrm{C}$.

Shock: $50 \mathrm{~g}$ at 0.1 milliseconds maximum.

Vibration: 10 to $2,000 \mathrm{~Hz}, 15 \mathrm{~g}$ peak.

Ingress protection of internal mechanisms exclusive of cable area: NEMA four.

Optional ingress protection: NEMA six.

\subsubsection{Pedal Force Transducer Design Specification}

\subsubsection{1}

Scope

This specification establishes the performance and design requirements for the pedal force transducer.

\subsubsection{Requirements}

\subsubsection{1 $\quad$ Item Definition}

The pedal force transducer shall be designed so that it is compact, rugged, and light weight. It shall accurately measure brake pedal application force regardless of the angle or position of the foot. The suspension flexure shall completely isolate the measuring section from the mounting base. Installation forces and variations in the geometry of the brake pedal on which the transducer is mounted shall have no effect on transducer accuracy. The pedal force transducer shall have a built-in positive overload stop which prevents damage to the transducer when loads beyond $150 \%$ of rated capacity are applied. It shall be able to be mounted to the pedal with four mounting bolts. The pedal force transducer shall be powered by a DC voltage input provided by the DASCAR stand alone power supply.

\subsection{Characteristics}

\subsection{Detailed Performance Specifications}


The pedal force transducer shall meet the following specifications.

Capacity: 136 kilograms, standard.

Bridge resistance: 350 ohms.

Linearity: $0.2 \%$ full scale.

Accuracy: within $2 \%$ for all possible locations of force applications.

Bridge excitation: $15 \mathrm{~V} \mathrm{DC}$ maximum.

Output: 1.5 millivolts (mV)/V full scale, nominal.

Weight: 426 grams nominal.

Cable: 2.44 meters heavy neoprene insulated (including connector).

Dimensions: 8.89 (diameter) $\times 11.43$ (length) $\times 2.80$ (height) centimeters.

\subsubsection{Accelerometer Design Specification}

\subsubsection{1 $\quad \underline{\text { Scope }}$}

This specification establishes the performance and design requirements for the accelerometer.

\subsubsection{2 $\quad$ Requirements}

\subsubsection{1 $\quad$ Item Definition}

The accelerometer shall be an inertial sensor consisting of single-crystal piezoelectric quartz in the shape of a double-ended tuning fork. The tines of one fork, driven by an oscillator at a precise amplitude, shall move toward and away from each other at a high frequency. This fork shall drive the other which produces the output signal. The forks, support flexures, and frame shall all be fabricated from a single wafer. The accelerometer shall be used to collect fidget index data from the vehicle driver. It shall be powered by a DC voltage input provided by the DASCAR stand alone power supply.

\subsection{Characteristics}

\subsection{Detailed Performance Specifications}

The accelerometer shall meet the following specifications.

\subsection{1 Power Requirements}

Input voltage: + and $-10 \mathrm{~V} \mathrm{DC}+/-2 \mathrm{~V} \mathrm{DC}$.

Input power: $<0.7 \mathrm{~W}$. 


\subsection{2 Performance}

Range: +/- 100 degrees/second

Scale factor: $15 \mathrm{mV} /$ degree$/$ second.

Bandwidth (-90 degrees): $>50 \mathrm{~Hz}$.

Damping: $0.8+/-0.2$ equivalent.

Start-up time: $<0.5$ seconds.

Scale factor calibration: $<2.0 \%$ of value.

Scale factor over operating temperature: within $+/-2 \%$ of room temperature.

Bias, short-term stability: $<0.005$ degrees/second, (100 seconds at constant temperature).

Bias, long-term stability: < one degree/second, (one year at constant temperature).

Bias $g$ sensitive: $<0.03$ degrees/second $/ g-z$ axis, $<0.003$ degrees $/$ second $/ g-x$ and $y$ axes.

Bias over operating environments: within $+/$ - four degrees/second (including initial settings).

Resolution/threshold: $<0.004$ degrees/second.

Linearity: $<0.05 \%$ of full range.

Output noise (typical): 0.012 degrees/second/square root $\mathrm{Hz}$ to $100 \mathrm{~Hz}$.

Operating life: 10 years, typical.

Mean time between failures (MTBF): > 100,000 hours.

\subsection{3 Environments}

Operating temperature: -40 to +80 degrees $\mathrm{C}$.

Storage temperature: -55 to +100 degrees $C$.

Vibration survival: $10 \mathrm{~g}$ RMS, 20 to $2,000-\mathrm{Hz}$ random.

Vibration operating: four $\mathrm{g}$ RMS, 20 to $2,000-\mathrm{Hz}$ random.

Shock survival: $100 \mathrm{~g}$, two milliseconds, $1 / 2$ sine.

\subsection{4 Pinout}

$\begin{array}{ll}\text { Pin } & \text { Assignment } \\ 1 & \text { - V DC } \\ 2 & + \text { V DC } \\ 3 & \text { Power ground } \\ 4 & \text { Signal ground } \\ 5 & \text { Rate output } \\ 6 & \text { Factory test } \\ 7 & \text { Built in test }\end{array}$

\subsubsection{Ambulatory Data Recording System Design Specification}

\subsubsection{1 $\quad$ Scope}


This specification establishes the performance and design requirements for the ADRS.

\subsubsection{Requirements}

\subsection{Item Definition}

The ADRS shall consist of boards, cables, electrodes, and fetrodes necessary to collect core temperature, electrocardiogram, electroencephalogram, electromyogram, electrooculogram, galvanic skin response, respiration, and skin temperature data from the driver. It shall contain one or more electronic enclosures and contain circuitry with the capability of accepting physiological signals from the motorist. The ADRS shall have the capacity to gather up to eight channels of physiological data from the driver over an extended period of time and be unaffected by motorist movement. The physiological signals shall be converted from analog format and processed digitally. The digital information shall be output to a RAM card which will be able to be read by the PC. Local access and control of the ADRS shall be via a key board. The ADRS shall be powered by an internal power supply.

\subsection{Characteristics}

\subsection{Detailed Performance Specifications}

The ADRS shall meet the following specifications.

\subsection{1 Physical}

Size: $10.2 \times 15.2 \times 3.81$ centimeters.

Weight: 623 grams.

Case: deep drawn aluminum-powder coated.

\subsection{2 Power Supply}

Battery: standard nine $\mathrm{V}$ alkaline.

Battery life: > 50 hours with one Mb RAM card.

\subsection{3 Data Storage}

Medium: PCMCIA (68 pin) one Mb RAM card (standard).

Backup: internal lithium battery backup ( $>$ one year).

Protection: internal write protect switch.

Down load: < one minute. 


\subsection{4 Miscellaneous}

Sample rate: software configured - shall support variable rates for different channels time. Time: a real-time clock shall encode time stamps in data field.

Event marks: five available - encoded in data field with time stamp.

Display: $16 \times 1$ characters - front panel display programmed to display continuous system status as well as incoming signal status, time, and keyboard activity.

\subsection{5 Analog Channels}

Resolution: eight bits.

All other analog characteristics shall be tailored to specific requirements.

\subsection{6 Skin Temperature Probe}

Converter: 12 bit analog to digital.

Temperature range: 0 to 40 degrees $C$.

Resolution: 0.1 degree.

Multiplexed on one channel.

\subsection{7 Respiration Transducer}

Sensor type: strain gauge, respond linearly to changes in abdominal and/or thoracic circumference.

Size: 5.08 (wide) $\times 0.318$ (thick) centimeters $\mathrm{x}$ adjustable length (regular size shall accommodate circumferences of 30 to over 254 centimeters).

Resistance: $200 \mathrm{ohms}$ (unit may vary $+/-50 \mathrm{ohms}$ ).

Wire length: 1.83 meters nominal, shall be able to be 15 meters or more without degradation of performance.

Connectors: as required.

Washable: yes.

\subsection{8 Quicklog}

Size: $15.2 \times 15.2 \times 6.35$ centimeters.

Weight: 567 grams.

Power: nine-V alkaline battery; battery life - 30 hours (continuous), three to six months average use.

Readout: 3.5 digit, $\mathrm{LCD} ; 0-2.55 \mathrm{~V}$ at output for a strip chart recorder.

Channels: one or two.

Sample rates: manual, automatic $-1,2,5,10$ per second. 


\subsection{9 Quicklog Software}

Computer supported: International Business Machines PC or compatible with 286, 386, or 486 processor.

Operating system: Microsoft DOS 3.1 or newer, and Windows 3.0 or 3.1. Functions: download and store data as American Standard Code for Information Interchange (ASCII) disk files; create and review short annotation messages; print PLOT sections; and recall previous files for analysis.

\subsection{10 SLICLog}

Size: $16.13 \times 24.13 \times 3.56$ centimeters.

Weight: 567 grams.

Channels: one or two.

Input connector: BNC.

Output connector: DB 25 (serial port).

Baud rate clock: crystal controlled.

Baud rates: $9,600,4,800,2,400$, and 300 .

Power: wall transformer type DC supply.

\subsubsection{Six Degrees of Freedom Orientation Sensor Design Specification}

\subsubsection{1 $\quad \underline{\text { Scope }}$}

This specification establishes the performance and design requirements for the six-DOF orientation sensor.

\subsubsection{Requirements}

\subsubsection{1 $\quad \underline{\text { Item Definition }}$}

The six-DOF orientation sensor shall consist of subminiature oscillating quartz elements and servoed quartz flexure pendulums necessary to collect acceleration (lateral, longitudinal, and vertical), pitch, row, and yaw data from the vehicle and road gradient data in the environment. It shall be solid-state technology and comprised of three GyroChips and three quartz flexure accelerometers sealed with micro electronics in a compact, ruggedized package. The six-DOF orientation sensor shall provide three high-level analog DC rate signal outputs and three high-level analog DC acceleration signal outputs, with a wide bandwidth frequency response. It shall be powered by a DC voltage input provided by the DASCAR stand alone power supply.

\subsection{Characteristics}

\subsection{Detailed Performance Specifications}


The six-DOF orientation sensor shall meet the following specifications.

\subsection{1 Power Requirements}

Input voltage: $+/-12.8$ to $+/-18.0 \mathrm{~V} \mathrm{DC}$.

Input power: $<3.3 \mathrm{~W}$.

\subsection{2 Life and Environment}

Weight: 816 grams.

Operating life: 10 years, typical.

MTBF: $>100,000$ hours.

Operating temperature: -40 to +80 degrees $\mathrm{C}$.

Storage temperature: -55 to +100 degrees $\mathrm{C}$.

Vibration survival: $10 \mathrm{~g}$ RMS, 20 to $2,000 \mathrm{~Hz}$ random.

Vibration operating: four g RMS, 20 to $2,000 \mathrm{~Hz}$ random.

Shock survival: $100 \mathrm{~g}$, two milliseconds, $1 / 2$ sine.

\subsection{3 Pinout}

$\begin{array}{ll}\frac{\text { Pin }}{1} & \text { Assignment } \\ 2 & \text { Power ground } \\ 3 & \text { Signal ground } \\ 4 & \text { Case ground } \\ 5 & \text { +15 V DC input } \\ 6 & \text {-15 V DC input } \\ 7 & \text { Rate x } \\ 8 & \text { Rate y } \\ 9 & \text { Rate } z \\ 10 & \text { Acceleration } x \\ 11 & \text { Acceleration y } \\ 12 & \text { Acceleration } z \\ & \text { Temperature sensor out }\end{array}$

\subsection{4 Rate Channel Performance}

Ranges available: $+/-10$ to $+/-1,000$ degrees/second.

Full scale output: $+/-2.5 \mathrm{~V}$ DC nominal.

Bandwidth ( -90 degrees): $>60 \mathrm{~Hz}$.

Damping: $0.7+/-0.3$ equivalent.

Start-up time: < one second.

Scale factor calibration: $<1.0 \%$ of value.

Scale factor T.C.: $<0.03 \% /$ degree C. 
Bias short term: $<0.005$ degrees/second, 100 seconds at constant temperature.

Bias long term: $<0.10$ degrees/second, one year at constant temperature.

Bias g sensitive: $<0.003 / \mathrm{second} / \mathrm{g}$ - sense axis, $<0.03 / \mathrm{second} / \mathrm{g}$ - cross axis.

Resolution/threshold: $<0.002$ degrees/second.

Linearity: $<0.05 \%$ of full range.

Output noise (typical): 0.012 degrees/second/square root $\mathrm{Hz}$ to $100 \mathrm{~Hz}$.

\subsection{5 Acceleration Channel Performance}

Range: $+/-$ three $g$.

Full scale output: $+/-$ nine-V DC nominal.

Bandwidth ( -90 degrees): $>300 \mathrm{~Hz}$.

Damping: $0.7+/-0.2$ equivalent.

Zero $\mathrm{g}$ bias: $<+/-12.5$ milligravities.

Bias T.C.: $<100$ microgravities/degree C.

Scale factor calibration: $3.0+/-10 \% \mathrm{~V} / \mathrm{g}$.

Scale factor T.C.: $<0.01 \% /$ degree C.

Non-linearity: < 10 microgravities/g squared.

Non-repeatability: $<600$ microgravities, third order model -40 to +150 degrees $\mathrm{C}$.

Alignment: $<+/$ - four milliradians.

Alignment T.C.: <+/- five microradians/degree C.

\subsubsection{Hall-Effect Sensor Design Specification}

\subsubsection{1 $\quad \underline{\text { Scope }}$}

This specification establishes the performance and design requirements for the Hall-effect sensor.

\subsubsection{2 $\quad$ Requirements}

\subsubsection{1 $\quad$ Item Definition}

The Hall-effect sensor shall be used to collect distance traveled and velocity data from the vehicle. It shall be a small sheet of semiconductor material activated by a magnetic field, and have integrated control circuits and an electronic switch. A constant voltage source shall cause a constant bias current to flow in the semiconductor sheet. The Hall-effect sensor shall be easily mounted (i.e., drop in, bolt in, and go) and have high data resolution. With the sensor one shall have true zero speed and power-up recognition. The Hall-effect sensor shall be powered by a DC voltage input provided by the DASCAR stand alone power supply.

\subsection{Characteristics}

\subsection{Detailed Performance Specifications}


The Hall-effect sensor shall meet the following specifications.

Input voltage: five $\mathrm{V}$ DC.

Output voltage: zero - five V square wave.

Sensor type: bipolar Hall-effect (north/south; north/south).

Connector: four-pin molex (ground; signal +; signal -; power).

Operating temperature: -40 to +150 degrees $\mathrm{C}$.

\subsubsection{Electronic Compass Design Specification}

\subsubsection{1 : $\quad \underline{\text { Scope }}$}

This specification establishes the performance and design requirements for the electronic compass.

\subsubsection{Requirements}

\subsubsection{1 $\quad$ Item Definition}

The electronic compass shall be a state-of-the-art microprocessor-controlled fluxgate compass subsystem which consists of a detachable toroidal fluxgate sensing element and a small electronic board. The fluxgate sensor element shall be a saturable ring core, free floating in an inert fluid within a cylindrical lexan housing. The purpose of the floating ring core shall be to keep the sensing element horizontal with respect to the earth. The electronic compass shall be used to collect heading data from the vehicle. It shall be a small and accurate magnetic heading sensor. Parameters such as baud rate, update rate, and damping shall be user selectable. The electronic compass shall be powered by a DC voltage input provided by the DASCAR stand alone power supply.

\subsection{Characteristics}

\subsection{Detailed Performance Specifications}

The electronic compass shall meet the following specifications.

\subsection{1 Performance}

Accuracy: $+/-0.5$ degrees or $+/-10$ mils RMS (SE-25 coil assembly and digital/serial outputs).

Repeatability: $+/-0.2$ degrees or $+/$ five mils (SE- 25 coil assembly and digital/serial outputs).

Resolution: 0.1 degree or one mil.

Dip angle: $+/-80$ degrees, maintains stated accuracy after autocal over $+/-80$ degrees magnetic dip angles. 
Tilt angle: $+/-16$ degrees (SE-25 coil) deviation $=+/-0.3$ degrees RMS, $+/-45$ degrees (SE-10 coil - gimbaled) deviation $=+/-0.5$ degrees RMS.

Electrical power: input voltage: +8 to $18 \mathrm{~V} \mathrm{DC}$ or +18 to $28 \mathrm{~V} \mathrm{DC}$ - user selectable; current drain: $40 \mathrm{~mA} \mathrm{DC}$, maximum.

Variation/declination: $+/-180.0$ degrees adjustment range (offset) - user selectable.

Index error offset: $+/-180.0$ degrees adjustment range (offset) - user selectable.

Damping: 0.1 to 24 seconds (to final value) - user selectable.

\subsection{2 Life and Environment}

Size: electronic board: $4.57 \times 7.11 \times 1.02$ centimeters; sensor board: $4.57 \times 4.01 \times 2.79$ centimeters (SE-25 coil); gimbaled coil (SE-10) hangs 4.32 centimeters below the PC board; combined board: $4.57 \times 11.43 \times 2.79$ centimeters (SE-25 coil).

Weight: 63.76 grams with SE-25 coil assembly.

Operating temperature: -6 to +50 degrees $\mathrm{C}$.

Storage temperature: -22 to +71 degrees $\mathrm{C}$.

Shock/vibration: designed to meet MIL-STD-810 shock and vibration requirements.

Altitude: designed to meet 12,192 meters MSL (operating and non-operating).

Readability: MTBF - calculated to exceed 30,000 hours.

\subsection{3 Digital Interfaces}

\subsection{3.1 $\quad \underline{\text { Serial Port }}$}

RS-232 compatible: bidirectional serial data, UART format with ASCII characters, (one start, eight data, one stop, no parity), 300 to 9,600-baud - user selectable.

Serial input: accept RS-232 levels or zero to +five V logic levels.

Serial output: same as RS-232 except for zero to +five V logic levels, (logic " 0 " $=+$ five V) 10,000 ohms - minimum load.

Inverse serial output: same as above serial output except logic " $1 "=+$ five $V$.

NEMA 0183: NEMA 0183 compatible bidirectional data/levels/formats.

\subsection{3.2 Digital Synchronous Port}

The digital outputs shall be user configurable to provide strobed or free running data at up to a 10 $\mathrm{Hz}$ message rate.

Strobe input: ground momentarily (one microsecond minimum) to obtain data output. Clock output: zero to +five $\mathrm{V}$ square wave at $10 \mathrm{kHz}$ rate.

Data output: four digit $\mathrm{BCD}, 16$ digit binary or 16 bit serial gray code, $\mathrm{C} 100$ display, NCSC - user selectable through serial port, 10,000 ohm minimum load on output signals. 


\subsection{4 Analog Outputs}

Sine/cosine/reference: output voltage $+1.5 \mathrm{~V}+/-1.0 \mathrm{~V}$, reference voltage $+1.5 \mathrm{~V} \mathrm{DC}$, $20,000 \mathrm{ohm}$ minimum load capacity.

Linear voltage: +0.1 to $+1.9 \mathrm{~V} \mathrm{DC}$ into $20,000 \mathrm{ohm}$ minimum load (five $\mathrm{mV} /$ degree slope).

Linear voltage with hysteresis: +0.105 to $+1.925 \mathrm{~V} \mathrm{DC}$ into 20,000 ohm minimum load (five $\mathrm{mV} /$ degrees slope).

\subsection{5 Features}

Heading type: variation off.

Powerup mode: sending.

Variation: 0 to $+/-359.9$ degrees or 0 to $+/-6399$ mils.

"A" offset: 0 to $+/-359.9$ degrees or 0 to $+/-6399$ mils.

Baud rate: 300 to 9,600 .

Message rate: up to 10 per second or on command.

Message type: NEMA, $\mathrm{X}$ and $\mathrm{Y}$ corrected and uncorrected.

Message units: degrees or mils.

Digital output type: continuous at a selected message rate or strobed.

Digital output format: $\mathrm{BCD}$, binary, gray.

Analog output format: sine/cosine/reference, linear, linear with hysteresis.

Damping type: undamped, single IIR, sum and dump, double IIR.

Damping rate: 3 to 24 seconds (to final value).

Autocal: user enabled.

\subsubsection{Range Sensors Design Specifications}

\subsubsection{Doppler Radar Sensor Design Specification}

\subsubsection{1 $\underline{\text { Scope }}$}

This specification establishes the performance and design requirements for the Doppler-radar sensor.

\subsubsection{2 $\quad$ Requirements}

\subsection{Item Definition}

The Doppler-radar sensor shall consist of boards, cables, antennas, transceiver/receiver assemblies, and central processors necessary to collect headway, tailway, and time-to-collision data from the vehicle. It shall comprise one or more electronic enclosures with external electrical connectors. The Doppler-radar sensor shall transmit and receive very low-power microwave 
energy. It shall be able to track both moving and stationary objects using Doppler phase shift principles. The Doppler-radar sensor shall be powered by a DC voltage input provided by the DASCAR stand alone power supply.

\subsection{Characteristics}

\subsection{1 Detailed Performance Specifications}

The Doppler-radar sensor shall meet the following specifications.

Vehicle closing rate: $0.11-44.7$ meters per second.

Operating range: $1-107$ meters typical.

Host vehicle speed: $0.22-53.64$ meters per second.

Power requirements: 12 to $24 \mathrm{~V} \mathrm{DC}, 20 \mathrm{~W}$ nominal.

Operating frequency: forward radar -24.125 gigahertz $(\mathrm{GHz})$, blind spot radar -10.525

$\mathrm{GHz}$.

Total system weight: 3.06 kilograms (approximate).

\subsubsection{2 $\quad$ Laser Sensor Design Specification}

\subsubsection{1 $\quad \underline{\text { Scope }}$}

This specification establishes the performance and design requirements for the laser sensor.

\subsubsection{2 $\quad$ Requirements}

\subsection{Item Definition}

The laser sensor shall consist of boards, cables, and transceiver/receiver assemblies necessary to collect headway, tailway, and time-to-collision data from the vehicle. It shall be small and lightweight and consist of one or more electronic enclosures with external electrical connectors. The laser sensor shall transmit and receive low-power, short laser pulses. It shall be able to track both moving and stationary objects using the principle of time-of-flight measurement. The laser sensor shall be powered by a DC voltage input provided by the DASCAR stand alone power supply.

\subsection{Characteristics}

Two laser sensors are being specified. The first provides headway and tailway measurement for great distances, cran distance measurement, and level measurement in great silos and is a position sensor for great distances. The second sensor measures distances to bad reflecting targets (e.g., level measurements in coal bunker, cross section measurements of dump, and height-of-flight measurements). 


\subsection{1 Detailed Performance Specifications for Laser Sensor \#1}

The first laser sensor shall meet the following specifications.

\subsection{1.1 Measuring Range}

The measuring range shall depend on the reflection characteristics of the target.

Good, diffusely reflecting targets, reflection coefficient greater than $80 \%$ : up to 120 meters (1).

Bad, diffusely reflecting targets, reflection coefficient greater than $10 \%$ : up to 40 meters (1).

Reflecting foil (2) or plastic cat's-eye reflectors: up to 1,000 meters.

Minimum distance (3): three to five meters.

\subsection{1.2 Distance Measurement}

Accuracy (typically) (4): $+/$ - five centimeters.

Measuring time (milliseconds or seconds) (5): 10,20 , or 50 milliseconds; $0.1,0.2,0.5$, 1.0 , or 2.0 seconds.

Statistical deviation (centimeters) $(6):+/-10,7,5,3,2,1.5,1$, or 0.7 .

Resolution (centimeters) $(6,7): 10,10,5,5,2,2,1$, or 1 .

\subsection{1.3 Serial Data Interface}

RS-232: V 24, bidirectional, baud rate adjustable between 150 and 19,200 .

RS-422: optional, for long transmission paths.

\subsection{1.4 Power Supply}

Standard 12 V DC: $11-18 \mathrm{~V} \mathrm{DC}$, approximately $10 \mathrm{~W}$ built-in protecting circuitry for over-voltage and reversal polarity.

Option 220 V AC: external power supply VNG 90, input voltage $220 \mathrm{~V} \mathrm{AC} / 50 \mathrm{~Hz}$; dimensions - $120 \times 120 \times 80$ millimeters.

\subsection{1.5 Temperature Range}

Operation: -10 to +50 degrees $\mathrm{C}$.

Storage: -20 to +60 degrees $\mathrm{C}$.

\subsection{1.6 $\quad$ Additional Data}

Dimensions: $220 \times 130 \times 76$ millimeters (length $\mathrm{x}$ width $\mathrm{x}$ height). 
Weight: approximately 1.5 kilograms.

Protection class: IP64, dust and splash-water-proof.

\subsection{1.7 Miscellaneous}

Divergence of the infrared (IR) measuring beam (8): 2.0 milliradians.

Eye safety class according to CENELEC EN 60825 (1991): laser class one.

\subsection{1.8 $\quad$ Notes}

(1) Typical values for average daylight conditions. In bright sunlight, the operational range shall be considerably shorter than under an overcast sky. At dawn or at night the range shall be even higher.

(2) Reflecting foil $3 \mathrm{M} 2,000 \mathrm{X}$ or equivalent, minimum dimensions $0.45 \times 0.45$ meters squared.

(3) Minimum distance, if requested, $>15$ meters to achieve a higher clutter suppression at smoke, fog, etc.

(4) Standard deviation, plus distance depending error < 20 PPM.

(5) Adjustable via RS-232. The RS-232 data output shall be useful only for measuring times of 50 milliseconds or more.

(6) Dependent on measuring time.

(7) Chosen automatically by the internal microprocessor.

(8) Two milliradians correspond to 20 centimeters beamwidth per 100 meters of distance.

\subsection{2 Detailed Performance Specifications for Laser Sensor \#2}

The second laser sensor shall meet the following specifications.

\subsection{2.1 Measuring Range}

The measuring range shall depend on the reflection characteristics of the target.

Good, diffusely reflecting targets, reflection coefficient greater than $80 \%$ : up to 300 meters (1).

Bad, diffusely reflecting targets, reflection coefficient greater than 10\%: up to 100 meters (1).

Reflecting foil (2) or plastic cat's-eye reflectors: up to 1,000 meters.

Minimum distance (typically): five meters.

\subsection{2.2 $\quad$ Distance Measurement}

Accuracy (typically) (3): $+/-10$ centimeters.

Measuring time (seconds) (4): $0.05,0.1,0.2,0.5,1$, or 2 . 
Statistical deviation (centimeters) (5): $+/-15,10,7,5,3,2$.

Resolution (centimeters) $(5,6): 10,10,5,5,2,2$.

\subsection{2.3 $\quad \underline{\text { Serial Data Interface }}$}

RS-232: V 24, bidirectional, baud rate adjustable between 150 and 19,200.

RS-422: optional, for long transmission paths.

\subsection{2.4 Power Supply}

Standard $12 \mathrm{~V} \mathrm{DC}$ : $11-18 \mathrm{~V} \mathrm{DC}$, approximately $10 \mathrm{~W}$ built-in protecting circuitry for over-voltage and reversal polarity.

Option 220 V AC: external power supply VNG 90 , input voltage $220 \mathrm{~V} \mathrm{AC} / 50 \mathrm{~Hz}$; dimensions - $120 \times 120 \times 80$ millimeters.

\subsection{2.5 Temperature Range}

Operation: -10 to +50 degrees $\mathrm{C}$.

Storage: -20 to +60 degrees $\mathrm{C}$.

\subsection{2.6 Additional Data}

Dimensions: $220 \times 130 \times 76$ millimeters (length $\mathrm{x}$ width $\mathrm{x}$ height).

Weight: approximately 1.5 kilograms.

Protection class: IP64, dust and splash-water-proof.

\subsection{2.7 Miscellaneous}

Divergence of the $\mathrm{IR}$ measuring beam (7): three milliradians.

Eye safety class according to CENELEC EN 60825 (1991): laser class one.

\subsection{2.8 $\quad \underline{\text { Notes }}$}

(1) Typical values for average daylight conditions. In bright sunlight, the operational range shall be considerably shorter than under an overcast sky. At dawn or at night the range shall be even higher.

(2) Reflecting foil $3 \mathrm{M} 2,000 \mathrm{X}$ or equivalent, minimum dimensions $0.45 \times 0.45$ meters squared.

(3) Standard deviation, plus distance depending error $<20$ PPM.

(4) Adjustable via RS-232.

(5) Dependent on measuring time.

(6) Chosen automatically by the internal microprocessor. 
(7) Three milliradians correspond to 30 centimeters beamwidth per 100 meters of distance.

\subsubsection{Controlaser Design Specification}

\subsubsection{1 $\underline{\text { Scope }}$}

This specification establishes the performance and design requirements for the controlaser.

\subsection{Requirements}

\subsection{1 $\quad \underline{\text { Item Definition }}$}

The controlaser shall consist of boards, cables, transceiver/receiver assemblies, and central processors necessary to collect headway, tailway, and time-to-collision data from the vehicle. It shall be small and lightweight and consist of one or more electronic enclosures with external electrical connectors. The controlaser shall transmit and receive low-power, short laser pulses. It shall be able to track both moving and stationary objects using the principle of time-of-flight measurement. The controlaser shall be powered by a DC voltage input provided by the DASCAR stand alone power supply.

\subsection{Characteristics}

\subsection{1 Detailed Performance Specifications}

The controlaser shall meet the following specifications.

Dimensions: 7.49 (width) $\times 13.00$ (length) $\times 7.01$ (height) centimeters (not including the mounting base).

Operating temperature: -1 to 70 degrees $C$; a high temperature LED shall light above 70 degrees $\mathrm{C}$ to indicate that the unit has ceased to function. The unit shall be automatically reactive when the temperature returns to the operating range.

Weight: 249.88 grams.

Effective range: shall be capable of measuring vehicles up to 100 meters ahead and behind (less in foggy weather).

Power requirements: five $\mathrm{W}$ at $12 \mathrm{~V}$.

Nonvolatile memory: shall be capable of storing all calibration and customer preference settings in nonvolatile memory. These settings shall be permanently retained even when the unit is turned off or disconnected from the DASCAR power supply.

Safety: conform to the IEC-825 and American National Standards Institute (ANSI) electrical impedance $(Z)$ 136.1 regulations concerning the safe use of lasers.

Warranty: one year. 


\subsubsection{Radiometer/Photometer Design Specification}

\subsubsection{1 $\underline{\text { Scope }}$}

This specification establishes the performance and design requirements for the radiometer/photometer.

\subsubsection{Requirements}

\subsubsection{1 $\quad \underline{\text { Item Definition }}$}

The radiometer/photometer shall consist of boards, cables, detectors, and microprocessors necessary to collect illumination and lumination data from the environment outside the vehicle. It shall be small and lightweight and contain one or more electronic enclosures with external electrical connectors. The radiometer/photometer shall provide automatic ranging and linear readout in real time. It shall be powered by a DC voltage input provided by the DASCAR stand alone power supply.

\subsection{Characteristics}

\subsection{Detailed Performance Specifications}

The radiometer/photometer shall meet the following specifications.

\subsection{1 Features}

Automatic ranging, including integration modes.

Light integration, seconds to 24 hours.

TTL serial printer/computer interface.

Smart detector determined processing.

User friendly alphanumeric display.

Direct reading in any optical units.

Analog recorder output (zero - one V).

Dark room hold reading feature.

Hand held - completely portable.

Automatic units displayed.

Seven decade dynamic range.

Automatic shut-off.

Automatic zeroing.

Battery operated. 


\subsection{2 Standard Units in Signal Mode}

W/centimeter squared, $W$, lumens/foot squared, lux, foot-lamberts, illuminance (E)/centimeter squared, candela/centimeter squared, candela/meter squared, A, W/centimeter squared/steradian, $\mathrm{W} /$ centimeter squared/nanometers, $\mathrm{dBu}$, and $\mathrm{dBm}$.

\subsection{3 Standard Units in Integrate Mode}

Joules/centimeter squared, Joules, lumens*s/foot squared, lux*s, foot-lamberts*s, E*s/centimeter squared, candela*s/centimeter squared, candela*s/meter squared, Coulombs, Joules/centimeter squared/steradian, Joules/centimeter squared/nanometers, $\mathrm{dBu} * \mathrm{~s}$, and $\mathrm{dBm}^{*} \mathrm{~s}$.

\subsection{4 Electrical/Mechanical}

Input power: four 'AA' alkaline batteries, $26 \mathrm{~mA}$.

Signal current: over seven decades of overlapping current measurement from 10 picoamperes to 350 microamperes.

Input impedance: virtual ground (summing node of operational amplifier).

Linearity: $+/-0.2 \%+/$ - one digit.

Recorder output: 408 ohm impedance, one V scale, current limited, 1/2 second update.

Size: 185 (height) x 100 (width) $\times 43$ (depth) millimeters.

\subsection{5 Illuminance Probe}

33 millimeters squared silicon detector.

Y photopic filter.

High gain lens.

YIS (IYIS) calibration for direct reading in foot-candles.

Spectral range: $400-700$ nanometers.

\subsection{6 Luminance Probe}

33 millimeters squared silicon detector.

Y photopic filter.

Radiance/luminance barrel.

YLS (IYLS) calibration for direct reading in foot-lamberts.

Measure luminance over a target area greater than 30 millimeters diameter plus 1.5 degree half angle divergence.

Spectral range: $400-700$ nanometers.

\subsubsection{Sound Level Meter Design Specification}

\subsubsection{1 $\underline{\text { Scope }}$}


This specification establishes the performance and design requirements for the sound level meter.

\subsubsection{2 $\quad$ Requirements}

\subsection{Item Definition}

The sound level meter shall consist of boards, cables, detectors, microphones, and microprocessors to collect steady state and impulse noise and sound as heard by the driver inside the vehicle. It shall be small, lightweight, and rugged, and comprise one or more electronic enclosures with external electrical connectors. The sound level meter shall have a removable microphone for remote measurement capability and a DC recording output. It shall be a type two general purpose sound level meter which provides wide dynamic range from $35-140 \mathrm{~dB}$. The sound level meter shall be powered by a DC voltage input provided by the DASCAR stand alone power supply.

\subsection{Characteristics}

\subsection{Detailed Performance Specifications}

The sound level meter shall meet the following specifications.

Range: meter only - 35 to $140 \mathrm{~dB}(\mathrm{~A})$; with external filters - 10 to $140 \mathrm{~dB}$. Noise floor shall vary depending on the filter frequency selected.

Standards: ANSI S1.4 type two and relevant sections of IEC 651.

Microphones: removable 2.11 centimeter prepolarized condenser (electret); microphone preamp - removable and shall drive up to 30.5 meters of cable.

Outputs: $\mathrm{AC}$ and $\mathrm{DC}$ for chart recorders.

Frequency weighting networks: A, B, C, and linear. When using an octave filter, any one of the weightings shall be selected.

Frequency range: $4 \mathrm{~Hz}(-3 \mathrm{~dB})$ to $50 \mathrm{KHz}(-3 \mathrm{~dB})$ linear scale, subject to microphone limitations.

Display: 8.9 centimeter digital crystal display with additional quasi-analogue $60 \mathrm{~dB}$ indicator in two $\mathrm{dB}$ increments; level display to $0.1 \mathrm{~dB}$ resolution; and annunciators for battery check, hold, and overload indicators.

Meter response: slow, fast, peak, and impulse in sound pressure level and MAX mode. Batteries: two nine-V batteries (NEDA 1604A) shall produce approximately 20 hours of continuous operation (10 hours with an optional filter).

Tripod mount: accept a standard 1/4-20 tripod mounting screw.

Temperature range: operation: -10 to +50 degrees $\mathrm{C}$; storage: -20 to +60 degrees $\mathrm{C}$ (less batteries).

Size: $8.4 \times 20.8 \times 4.6$ centimeters, not including preamp height.

Weight: 680 grams including preamp, microphone, and batteries. 


\subsubsection{Meteorological Sensor Design Specification}

\subsubsection{1 $\quad \underline{\text { Scope }}$}

This specification establishes the performance and design requirements for the meteorological sensor.

\subsubsection{2 $\underline{\text { Requirements }}$}

\subsubsection{1 $\quad$ Item Definition}

The meteorological sensor shall use thermal resistive film technology to collect barometric pressure, humidity, temperature, and wind direction and speed data in the environment outside the vehicle. It shall have no moving parts. The elements of the meteorological sensor shall be electrically isolated but mechanically joined together in pairs. Wind speed shall be determined by the amount of electrical current required to maintain a controlled temperature in each element. With two pairs of elements mounted perpendicular to each other, wind direction shall be able to be calculated. The meteorological sensor shall provide high speed response to transient flow conditions and withstand extreme vibration and shock loads. It shall be powered by a DC voltage input provided by the DASCAR stand alone power supply.

\subsection{Characteristics}

\subsection{Detailed Performance Specifications}

The meteorological sensor shall meet the following specifications.

Headwind range: two - four meters/second and 5 - 40 meters/second.

Headwind tolerance: 0.5 meters $/$ second and $+/-5 \%$.

Crosswind range: two - four meters/second and 5 - 40 meters/second.

Crosswind tolerance: 0.5 meters/second and $+/-5 \%$.

Barometric pressure range: $500-1,080$ millibars.

Barometric pressure tolerance: $+/$ - two millibars at room temperature.

Temperature range: -40 to +60 degrees $\mathrm{C}$.

Temperature tolerance: $+/$ - two degrees $\mathrm{C}$ at a minimum of five meters/second wind.

\subsection{Video Data System Design Specifications}

\subsubsection{Micro Camera Design Specifications}

\subsubsection{1 $\quad \underline{\text { Scope }}$}

This specification establishes the performance and design requirements for the micro cameras. 


\subsubsection{Requirements}

\subsection{Item Definition}

The micro cameras shall consist of camera heads, lenses, pick up devices, and cables to collect video data inside the vehicle and in the outside environment. The micro camera heads shall be small, measuring less than 2.5 centimeters in diameter and four centimeters in length and weighing less than 23 grams. The micro cameras shall have 336,000 pixel 1.27 centimeter charge coupled devices (CCD), with a horizontal resolution of 430 lines, and have outstanding resistance to vibration, shock, and magnetism. They shall be powered by a DC voltage input provided by the DASCAR stand alone power supply.

\subsection{Characteristics}

Two micro cameras are being specified. The first is a remote-head CCD digital color micro camera. The second is a remote-head CCD black-and-white micro camera.

\subsection{General Functional Requirements}

The micro cameras shall perform the following general functions.

\subsection{1 Environment Parameter Acquisition}

The micro cameras shall have the capability and capacity to record environment data.

\subsection{1.1 $\quad$ Car Lights}

The micro cameras shall have the capability and capacity to record the presence of car lights in the environment outside the vehicle.

\subsection{1.2 $\quad$ Delineation}

The micro cameras shall have the capability and capacity to record road delineation, both curved and straight.

\subsection{1.3 Distracting Lights, Obstacles, and Signs}

The micro cameras shall have the capability and capacity to record the presence of distracting lights, obstacles, and signs in the environment outside the vehicle. 


\subsection{1.4 Exits}

The micro cameras shall have the capability and capacity to record the presence and spacing of highway exit ramps.

\subsection{1.5 $\quad$ Hand Positions}

The micro cameras shall have the capability and capacity to record the right and left-hand positions of the driver

\subsection{1.6 $\quad \underline{\text { Haze/Dust }}$}

The micro cameras shall have the capability and capacity to record the presence of haze/dust in the environment outside the vehicle.

\subsection{1.7 $\quad$ Head Movements}

The micro cameras shall have the capability and capacity to record head movements of the driver.

\subsection{1.8 Intersections}

The micro cameras shall have the capability and capacity to record the presence and spacing of road intersections.

\subsection{1.9 Lane Vehicle Is In}

The micro cameras shall have the capability and capacity to record the lane the vehicle is in.

\subsection{1.10 One- or Two-way Traffic}

The micro cameras shall have the capability and capacity to record the presence of one and twoway traffic in the environment outside the vehicle.

\subsection{1.11 $\quad$ Parked Vehicles/Pedestrians}

The micro cameras shall have the capability and capacity to record the presence and spacing of parked vehicles and the presence and density of pedestrians.

\subsection{1.12 Precipitation}

The micro cameras shall have the capability and capacity to record the presence and type of precipitation in the outside environment. 


\subsection{1.13 $\quad$ Road Lighting, Surfaces, and Types}

The micro cameras shall have the capability and capacity to record the presence of road lighting, the kind of road surface (paved or unpaved), and road types (divided or undivided, and rural or urban).

\subsection{1.14 Surrounding Field of View}

The micro cameras shall have the capability and capacity to record the surrounding field of view inside the vehicle and outside the vehicle, both ahead and behind.

\subsection{1.15 Traffic Conditions, Events, and Lights}

The micro cameras shall have the capability and capacity to record: the traffic conditions, including congestion, mix of vehicles, and proximity of the vehicles; traffic events, both disturbances and situations; and the presence and spacing of traffic lights

\subsection{1.16 $\underline{\text { Turns/Hills }}$}

The micro cameras shall have the capability and capacity to record the presence and spacing of turns and hills.

\subsection{Detailed Performance Specifications for the Remote-head CCD Digital Color Micro Camera}

The remote head CCD digital color micro cameras shall meet the following specifications.

Pick up device: $682(\mathrm{H}) \times 492(\mathrm{~V})$ pixels, 1.27 centimeter integrated color filter interline transfer CCD.

Scanning system: $2: 1$ interlace.

Scanning: 525 lines/ 60 fields/ 30 frames; horizontal: $15.734 \mathrm{kHz}$; and vertical: $59.94 \mathrm{~Hz}$. Horizontal resolution: 430 lines.

Video output: one V p-p National Television Systems Committee (NTSC) composite, 75 ohms/BNC connector; composite video or Y/C out for super VHS recorder.

Signal-to-noise ratio: $46 \mathrm{~dB}$ (automatic gain control off).

Electronic light control: equivalent to continuous variable shutter speed between 1/60seconds and $1 / 15,700$-seconds.

Minimum scene illumination: five lux at $\mathrm{F} 1.6$ (automatic gain control on; $+12 \mathrm{~dB}$ ), 3,200 degrees kelvin (K).

White balance (through the lens): auto white balance control/auto-tracing white balance/manual white balance control selectable.

Blacklight compensation: preset on (factory setup); preset off (manual setup at field); photometry area shall be selectable ( 25 blocks); and signal level shall be adjustable. 
Synchronization system: internal or external (HD/VD/VBS/VS) synchronization shall be selectable. H-PHASE adjustment in the VBS, VS, gen-lock; SC-PHASE adjustment in VBS, gen-lock mode.

Electronic shutter speed: selectable $1 / 60$ (off); 1/100;1/250;1/500;1/1,000;1/2,000; $1 / 4,000 ; 1 / 10,000$ - seconds.

Automatic gain control: off/low/mid/high selectable.

Gain control: automatic gain control off or on: $(+6 \mathrm{~dB},+9 \mathrm{~dB},+12 \mathrm{~dB})$; manual gain: (0 $\mathrm{dB},+6 \mathrm{~dB},+9 \mathrm{~dB},+12 \mathrm{~dB})$.

Camera identification: maximum 16 characters.

Special adjustment: chroma gain, hue, aperture gain, pedestal.

Lens mount: special mount (C-mount adapter shall be available).

Connectors: character generator input, 16-pin camera cable connector, composite video output (BNC), Y/C output, and $\mathrm{HD}, \mathrm{VD}$ input (BNC).

Ambient temperature: -10 to +50 degrees $C$.

Power source: $12 \mathrm{~V} \mathrm{DC}, 500 \mathrm{~mA}$.

Dimensions: camera head (excluding lens): 1.69 (diameter) $\times 3.81$ (length) centimeters; camera control unit: 11.91 (width) $\times 3.65$ (height) $\times 15.56$ (depth) centimeters.

Weight: camera head (excluding lens): 18 grams; camera control unit: 726 grams.

Standard accessories: tripod attachment: one piece; lens cleaning paper: one sheet.

Optional accessories: cables: GP-CA56, two meters; GP-CA57, 10.1 meters. lens: GPLM7R5TA, 7.5 millimeters (wide-angle).

\subsection{Detailed Performance Specifications for the Remote-head CCD Black-and-White Micro Camera}

The remote head CCD black-and-white micro cameras shall meet the following specifications.

Pick up device: 1.27 centimeter interline transfer $\mathrm{CCD}, 682(\mathrm{H}) \times 485(\mathrm{~V})$ pixels.

Scanning system: $2: 1$ interlace.

Synchronization system: internal or external (VS, HD-VD, genlock).

Horizontal resolution: 500 lines.

Signal-to-noise ratio: $50 \mathrm{~dB}$ with automatic gain control off.

Gain control: automatic gain control off or on $(+$ nine $\mathrm{dB})$; manual gain: zero $\mathrm{dB},+$ six dB.

Minimum illumination: 0.5 lux at F1.4, 2,856 degrees $\mathrm{K}$.

Lens mount: special mount (C-mount adaptor shall be available).

Connectors: 12-pin camera cable connector and composite video out (BNC).

Shock resistance: $80 \mathrm{~g}$ IEC 68-2-27.

Ambient temperature: -10 to +40 degrees $\mathrm{C}$.

Power: +12 V DC, six W.

Head dimensions (approximate): 1.69 (diameter) x 3.65 (length) centimeters.

Head weight: 18 grams. 
Cables: GP-CA44 (two meters), GP-CA48 (10 meters), GP-CA45 (five meters), and GPCA49 (30 meters).

Lens: GP-LM7R5TA 7.5 millimeters (wide-angle).

\subsubsection{Vertical Interval Time Code Generator Design Specification}

\subsubsection{1 $\quad \underline{\text { Scope }}$}

This specification establishes the performance and design requirements for the vertical interval time code (VITC) generator.

\subsubsection{2 $\quad$ Requirements}

\subsection{Item Definition}

The VITC generator shall consist of boards and cables necessary to time code the video output from the micro cameras. It shall be small and lightweight and contain one or more electronic enclosures with external electrical connectors. The VITC generator shall produce industry standard VITC time code and translate longitudinal time code time code into VITC time code. It shall be powered by a DC voltage input provided by the DASCAR stand alone power supply.

\subsection{Characteristics}

\subsection{Detailed Performance Specifications}

The VITC generator shall meet the following specifications.

\subsection{1 Power}

Operation: 9 to $13.5 \mathrm{~V} \mathrm{DC}, 250 \mathrm{~mA}$

Connector: 3.5 millimeters mini-phone jack.

$\mathrm{AC}$ adapter: nine $\mathrm{V}, 500 \mathrm{~mA}$.

\subsection{2 Video}

Standard: NTSC 525 line, 60 field, RS-170A.

Input level: one $\mathrm{V}$ p-p.

Input impedance: 75 ohms.

Output: power on: one $\mathrm{V} \mathrm{p}$-p (terminated at $75 \mathrm{ohms}$ ); power off: same as input (direct loop through).

Connectors: BNC. 


\subsection{3 VITC Time Code}

Format: SMPTE 90-bit drop-frame / non-drop-frame.

Output level: 0 IRE to $+90+/-10$ IRE.

\subsection{4 Longitudinal Time Code Time Code}

Format: SMPTE 80-bit longitudinal drop-frame / non-drop-frame.

Input level: $100 \mathrm{mV}$ to $10 \mathrm{~V} \mathrm{p}$-p.

Input impedance: $10,000 \mathrm{ohms}$, single ended.

Input speed: play speed, $+/-10 \%$.

Output level: $1.5 \mathrm{~V} \mathrm{p}$-p.

Output impedance: 2,000 ohms.

Output rise time: 25 microseconds, $+/$ - five microseconds.

Connectors: RCA.

\subsection{5 Preset}

Time-code: hours 00 to 23 , minutes 00 to 59 , drop-frame / non-drop-frame

User-bits: hexadecimal 0, 1, 2, 3, 4, 5, 6, 7, 8, 9, A, B, C, D, E, F.

\subsection{6 Display}

Format: hours, minutes, seconds, frames, HR:MN:SC:FR (23:59:59:29 maximum).

Drop-frame indicator: semicolon separating seconds and frames.

Field-1 indicator: period separating seconds and frames.

\subsection{7 $\underline{\text { Switches }}$}

Power: on/off.

Mode: TRN LTC/GEN/SET.

Display: SEL time-code, user bits, and off.

Line set: odd/even and 11/13,12/14, 13/15, 14/16, 15/17, and 16/18.

\subsection{8 LED Indicator}

Power ON (RDR): steady on.

Generator running: video - fast flashing; no video - alternating fast/slow flashing.

Stopped: video - medium flashing; no video - slow flashing.

\subsection{9 Remote Input: Field Pack Only}

Connector: 2.5 millimeters micro-mini phone jack. 
Signal level: 0 to $18 \mathrm{~V} \mathrm{DC}$. Zero $\mathrm{V}$ or a positive voltage from +3 to $18 \mathrm{~V}$ can either be start or stop, depending on actuation of mode.

\subsection{10 Environment}

Operating: 5 to 40 degrees $\mathrm{C}$.

Storage: -10 to 60 degrees $\mathrm{C}$.

\subsection{Dimensions}

Desktop: 5.1 (height) $\times 7.6$ (width) $\times 10.2$ (depth) centimeters.

Field pack: 4.45 (height) $\times 8.13$ (width) $\times 12.7$ (depth) centimeters.

Rackmount: 4.4 .5 (height) $\times 48.3$ (width) $\times 14.6$ (depth) centimeters.

Shortrack: 4.45 (height) x 17.8 (width) x 14.6 (depth) centimeters.

\subsection{Weight}

Desktop: 227 grams.

Field pack: 312 grams.

Rackmount: 680 grams.

Shortrack: 624 grams.

\subsubsection{Quad Picture Processor Design Specification}

\subsubsection{1 $\underline{\text { Scope }}$}

This specification establishes the performance and design requirements for the quad picture processor.

\subsubsection{2 $\quad \underline{\text { Requirements }}$}

\subsection{Item Definition}

The quad picture processor shall consist of boards and cables necessary to display, tape record, or transmit the pictures from four video micro cameras at one time. It shall be small and lightweight and consist of one or more electronic enclosures with external electrical connectors. The quad picture processor shall compress the pictures to one-fourth their size and digitally process the video. It shall be super VHS recorder and CVDSRS compatible and be capable of processing color video. The quad picture processor shall be powered by a DC voltage input provided by the DASCAR stand alone power supply. 


\subsection{Characteristics}

\subsection{Detailed Performance Specifications}

The quad picture processor shall meet the following specifications.

Video standard: NTSC: 525 lines, 60 fields/second; PAL: 625 lines, 50 fields/second. Video inputs: one V p-p composite, 75 ohms or high Z, BNC. Monitor output: one V pp composite video, 75 ohms, BNC

Video cassette recorder (VCR) input: one V p-p composite video, $75 \mathrm{ohms,} \mathrm{BNC;} \mathrm{or} \mathrm{one}$ V p-p S-luma (y), 75 ohms, S-video; 0.286 V p-p S-chroma (c), 75 ohms, S-video.

VCR output: one V p-p composite video into 75 ohms, BNC; and one V p-p S-luma (y), 75 ohms, S-video; $0.286 \mathrm{~V}$ p-p S-chroma (c), 75 ohms, S-video.

Digital memory: $512 \times 512$ pixels full screen; $256 \times 256$ pixels per quadrant; eight-bit luma, 256 shades of grey; and seven-bit chroma, more than four million colors on a pallet. Display rate: real-time refresh rate.

Alarm inputs: (four); dry contact closures.

Alarm outputs: (one); normally open or closed contacts; two $\mathrm{A}$ at $30 \mathrm{~V} \mathrm{DC}$ or one $\mathrm{A}$ at $120 \mathrm{~V} \mathrm{AC}$, resistive.

Alarm duration: four second minimum duration pulse.

Alarm hold input: +5 to $15 \mathrm{~V} \mathrm{DC}$ or TTL active high.

Operating voltage: $12 \mathrm{~V} \mathrm{DC}$; less than $10 \mathrm{~W}$.

Ambient temperature: 4 to 40 degrees $\mathrm{C}$.

Weight: 3.17 kilograms.

Dimensions: 4.45 (height) $\times 21.6$ (width) $\times 31.12$ (depth) centimeters.

Power: $10 \mathrm{~W}$.

\subsubsection{Compressed Video Digital Storage and Retrieval System Design Specification}

\subsubsection{1 $\underline{\text { Scope }}$}

This specification establishes the performance and design requirements for the CVDSRS.

\subsubsection{2 $\quad$ Requirements}

\subsection{Item Definition}

The CVDSRS shall consist of compression, storage, and retrieval equipment necessary to handle video from the micro cameras installed within and around the vehicle. It shall digitize and compress analog video material in real time via a moving pictures experts group (MPEG) encoder. The digitized video data shall not have to be transmitted as soon as the signals are compressed; rather, both video and audio shall be able to be stored together digitally on a hard disk drive, digital tape, optical disk, or any other digital storage device. Using standard computer 
and data transmission technologies, the digital files shall be able to be retrieved and directed to the appropriate destination at the exact time desired. The CVDSRS shall comprise five basic components: the MPEG encoder and four PC boards. It shall be powered by the DASCAR stand alone power supply.

\subsection{Characteristics}

\subsection{General Functional Requirements}

The CVDSRS shall perform the following general functions.

\subsection{1 Encoder}

The CVDSRS encoder shall have the capability to digitally compress the analog video and audio source material, using the MPEG standard, in real time. The process shall include converting the signals and storing them as a computer data file. Source video and audio input shall be received from a VTR and output in digital form to a PC, which shall control both the encoder and the VTR.

\subsection{2 PC Record Board}

The PC record board shall format the MPEG compressed video and audio from the encoder into a single bit stream suitable for direct storage on standard digital devices. It shall interface with a digital storage device via high-speed SCSI-two technology. The PC record board shall be located within the PC that is interfaced to the encoder. The data file shall be able to be passed to either a local video server or a PC uplink board for distribution over a satellite.

\subsection{3 PC Uplink and Transport Boards}

The PC uplink board shall interface with the satellite transmission system and allow for movement of the compressed video files and other control information between encoders, libraries, and decoders. The transport boards shall be capable of transporting the compressed data files via dialup modulators/demodulators, T1 links, fiber, and microwave circuits.

\subsection{4 PC Decoder}

The PC decoder shall convert the digital data stream back to NTSC video and stereo components for transmission through an analog cable plant or for display on a television or monitor. It shall be installed in a PC, using an ISA bus, where the PC decoder receives the compressed video data files in either real time or from a digital storage device. 


\subsection{Detailed Performance Specifications}

The CVDSRS shall meet the following specifications.

\subsection{1 Mechanical}

Power: automatic sensing universal input accepting 98 to $240 \mathrm{~V} \mathrm{AC}$ at 50 to $60 \mathrm{~Hz}$. Size: 17.78 (height) $\times 48.26$ (width) $\times 53.34$ (depth) centimeters.

Weight: approximately nine kilograms.

Storage temperature: -20 to 125 degrees $\mathrm{C}$.

Operating temperature: 0 to 40 degrees $\mathrm{C}$.

Operating humidity range: 10 to $90 \%$ non-condensing.

\subsection{2 Video Encoder Board}

Video encoding: single channel MPEG-1; I, B, and P frames.

Resolution: meet CCIR-601.

Horizontal resolution: $704,544,480$, and 352 pixels (user controlled).

Vertical resolution: 480 lines.

Inputs accepted: NTSC or component video (CCIR-656).

Bit rates: $5.3-8.3 \mathrm{Mb}$ per second.

Bit stream protocol: two-channel MPEG layer II.

Dimensions: 17.78 (height) $\times 33.53$ (depth) $\times 48.26$ (width) centimeters (Electronics Industry Association rack compatible).

Digital storage interface: PC record board (SCSI-two compatible).

\subsection{3 Video Input Board}

Video input: NTSC (RS-170).

Video input level: one $\mathrm{V}$ p-p $+/$ - one $\mathrm{V}$.

Input impedance: $75 \mathrm{ohms}$.

Input return loss: $0.20 \mathrm{~dB}$.

Input connector type: $\mathrm{BNC}$.

\subsection{4 MPEG Audio Encoder Board}

Input type: balanced, XLR inputs.

Impedance: high impedance ( $100 \mathrm{ohms})$ driven by a 600 -ohm source.

Input level: $+18 \mathrm{dBu}$ nominal.

Input adjustment range: +12 to $+24 \mathrm{dBu}$.

Frequency response: $+/-0.25 \mathrm{~dB}$ from 20 to $20,000 \mathrm{~Hz}$.

THD: $<0.25 \%$, full scale, 20 to $20,000 \mathrm{~Hz}$.

Hum and noise: $<86 \mathrm{~dB}$, A-weighted. 
Crosstalk isolation: $>75 \mathrm{~dB}, 20$ to $20,000 \mathrm{~Hz}$, reference in other channel.

Encode algorithm: MPEG-1, layer two, psycho-acoustic model \#1, dual channel mode.

Sampling rate: $48 \mathrm{kHz}$.

Compressed data rate: 256,000 bps.

Emphasis: none.

\subsection{5 Decoder}

Digital input: via onboard SCSI-two controller.

Video decoding: MPEG-1; all formats, rates, and resolutions supported by the encoder.

Video output: NTSC.

Video connector: BNC.

Audio output/audio connector: two channels (one stereo pair) via a quick-connect barrier strip.

Frequency response: $+/-25 \mathrm{~dB}$ at 20 to $20,000 \mathrm{~Hz}$.

Total harmonic distortion: $<.25 \%$ at 20 to $20,000 \mathrm{~Hz}$.

Size: set of two full-length PC/AT (ISA interface).

Capacity: one to eight decoder card sets per PC (depending on chassis size and storage configuration).

Minimum PC requirements: $25 \mathrm{MHz} 386 \mathrm{DX}$ with industrial cooling.

\subsection{6 Digital Storage}

Minimum hard disk: SCSI-two with the sustained data transfer rate $>$ two Mb per second and full stroke seek time $<40$ milliseconds.

Expandable to meet storage requirements using various media, i.e., hard disk, digital tape, and optical read/write.

Software: wide range of software drivers provided to permit customization of applications. The high-level software interface shall allow the boards to run autonomously, leaving the PC free to run other tasks.

\subsection{7 Simple Mux Board}

Connection type: differential terminated.

Levels/protocol: RS-485.

Duplex: synchronous.

Data bits: eight.

Data rate: $3.14 \times 10$ to the sixth power bps.

\subsection{8 Serial Data - Status/Control Link}

Baud rate: 57,600 .

Parity: no parity. 
Data bits: eight.

Stop bits: one.

Duplex: half duplex.

Levels/protocols: RS-232C.

\subsubsection{Super VHS Recorder Design Specification}

\subsubsection{1 $\underline{\text { Scope }}$}

This specification establishes the performance and design requirements for the super VHS recorder.

\subsubsection{2 $\quad$ Requirements}

\subsection{Item Definition}

The super VHS recorder shall consist of boards, cables, and super VHS tapes necessary to collect video from the micro cameras installed within and around the vehicle. It shall be lightweight, portable, and made of rugged construction and consist of one or more electronic enclosures with external electrical connectors. The super VHS recorder shall generate high quality pictures via a built-in chroma noise reduction technique and have high quality sound. It shall be powered by a DC voltage input provided by the DASCAR stand alone power supply.

\subsection{Characteristics}

\subsection{Detailed Performance Specifications}

The super VHS recorder shall meet the following specifications.

\subsection{1 General}

Format: VHS / super VHS standard.

Recording system: luminance FM recording; color - down-converted subcarrier/separated Y/C signals.

Signal system: NTSC.

Tape speed: 33.35 millimeters/second.

Record play time: 120 minutes (with T-120 / ST-120 cassettes).

Fast forward/rewind time: within four minutes (with T-120/ST-120 cassettes).

Power source: $12 \mathrm{~V} \mathrm{DC}$.

Power consumption: $19 \mathrm{~W}$.

Dimensions: 280 (width) $\times 1128$ (height) $\times 324$ (depth) millimeters.

Weight: 5.22 kilograms. 
Operating temperature: 0 to 40 degrees $\mathrm{C}$.

Storage temperature: -20 to 60 degrees $\mathrm{C}$.

\subsection{2 Video}

Input: 0.5 to $2.0 \mathrm{~V} \mathrm{p}-\mathrm{p}, 75 \mathrm{ohms}$ unbalanced.

Output: one V p-p, 75 ohms unbalanced.

Y/C input: $Y$ - one V p-p, 75 ohms unbalanced; $C-0.286 \mathrm{~V} p-p, 75$ ohms unbalanced (burst).

Y/C output: Y - one V p-p, 75 ohms unbalanced; C - 0.286 V p-p, 75 ohms unbalanced (burst).

Horizontal resolution: more than 240 lines (VHS color); more than 400 lines (super VHS color).

Signal-to-noise ratio: $46 \mathrm{~dB}$ (super VHS); $46 \mathrm{~dB}$ (VHS) (detail off).

\subsection{3 Audio}

Number of channels: two high fidelity channels / two normal channels.

Input: $-60 \mathrm{~dB}(3,000 \mathrm{ohms}) /-20 /+4 \mathrm{~dB}(10,000 \mathrm{ohms})$ balanced (high fidelity and normal).

Output: -six dB, 1,000 ohms, unbalanced (high fidelity and normal).

Headphone output: -48 to $+25 \mathrm{~dB}$, eight ohms.

\subsection{4 High Fidelity Audio}

Frequency response: 20 to $20,000 \mathrm{~Hz}$.

Dynamic range: more than $80 \mathrm{~dB}$.

Wow and flutter: $0.007 \%$ WRMS.

\subsection{5 Normal Audio}

Frequency response: 40 to $12,000 \mathrm{~Hz}$.

Signal-to-noise ratio: more than $44 \mathrm{~dB}$.

Wow and flutter: within $0.25 \%$ RMS.

\section{REFERENCE}

Department of Defense (1968). "Specification Practices," MIL-STD 490. 


\section{ACRONYMS AND ABBREVIATIONS}

A

AC

ADRS

ANSI

ASCII

BIOS

bps

C

CCD

CCIITT

CPU

CVDSRS

DAP

DASCAR

$\mathrm{dB}$

DC

DOF

DOS

E

EPA

EPROM

FCC

FFT

FM

$\mathrm{g}$

$\mathrm{GHz}$

GPS

$\mathrm{Hz}$

$\mathbb{R}$

K

$\mathrm{kb}$

$\mathrm{kHz}$ amperes

alternating current

ambulatory data recording system

American National Standards Institute

American Standard Code for Information Interchange

basic input output system

bits per second

Celsius

charge coupled device

International Telegraph and Telephone Consultative Committee central processing unit

compressed video digital storage and retrieval system

data acquisition platform

data acquisition system for crash avoidance research

decibels

direct current

degrees of freedom

disk operating system

illuminance

Environmental Protection Agency

electronic processing read-only memory

Federal Communications Commission

Fast Fourier Transform

frequency modulation

gravity

gigahertz

global positioning system

hertz

infrared

kelvin

kilobytes

kilohertz 
liquid crystal display

LED light emitting diode

$\mathrm{mA}$

milliamperes

$\mathrm{Mb}$

megabytes

$\mathrm{MHz}$

megahertz

MIL-STD

MPEG

military standard

MTBF

moving picture experts group

$\mathrm{mV}$

mean time between failures

millivolts

NEMA

National Electrical Manufacturer's Association

NHTSA

National Highway Traffic Safety Administration

NTSC

National Television Systems Committee

PC

PCMCIA

personal computer

Personal Computer Memory Card International Association

R

RAM

resolution

RMS

random access memory

root-mean square

SCSI

small computer system interface

UL

Underwriter's Laboratories

$\mathrm{V}$

VCR

VITC

volts

video cassette recorder

vertical interval time code

W

watts

Z

electrical impedance 

ORNL/TM-13540, Volume 3

\section{INTERNAL DISTRIBUTION}

1 - 5. R. J. Carter

6.

7. H. E. Knee

8. M. A. Kuliasha

9. C. E. Oliver

10. J. C. Schryver

11. P. F. Spelt
12.

13.

14.

15.

16.

17.
D. R. Tufano

Central Research Library

CSMD Reports Office

Document Reference Section

Laboratory Records-RC

ORNL Patent Office

\section{EXTERNAL DISTRIBUTION}

18 - 22. Frank S. Barickman, Transportation Research Center, Incorporated, P.O. Box B-37, East Liberty, OH 43319-0337

23 - 27. Michael J. Goodman, National Highway Traffic Safety Administration, 400 7th Street, SW, NRD-50, Washington, D.C. 20590

28 - 29. Office of Scientific and Technical Information, P. O. Box 62, Oak Ridge, TN 37831 